\title{
Vattenkemi och fiskbeståndens sammansättning i storlommens Gavia arctica häckningssjöar, samt en jämförelse med smålommens Gavia stellata fiskesjöar
}

\author{
Water chemistry and the composition of fish stocks in the breeding lakes of Black- \\ throated Diver Gavia arctica, and a comparison with the fishing lakes of Red- \\ throated Diver Gavia stellata
}

MATS O.G. ERIKSSON \& HEIDI PALTTO

\begin{tabular}{|c|c|}
\hline $\begin{array}{l}\text { Breeding performance of Black-throated Diver Gavia } \\
\text { arctica was compared to water chemistry, light penetra- } \\
\text { tion and density of fish in } 122 \text { breeding lakes in Sweden } \\
\text { with a total of } 184 \text { pairs ( } 1.5 \text { pairs per lake, about } 3 \% \text { of } \\
\text { the national population). The breeding lakes were on av- } \\
\text { erage nutrient-poor, and } 12 \% \text { of them had a low buffering } \\
\text { capacity (alkalinity }<0.10 \text { meq/l). Perch Perca fluviatilis, } \\
\text { roach Rutilus rutilus and pike Esox lucius, three species } \\
\text { characteristic for nutrient-poor lakes, were found in more } \\
\text { than } 90 \% \text { of the lakes. Salmonid fish occurred in half of } \\
\text { the lakes, compared to }>90 \% \text { of the fishing lakes used } \\
\text { by Red-throated Diver. Reproduction was related to high } \\
\text { abundance of Perch, and the survival of chicks to light } \\
\text { penetration. Poor nutrient status in combination with low }\end{array}$ & $\begin{array}{l}\mathrm{pH} \text { or alkalinity in approximatively } 10 \% \text { of the breeding } \\
\text { lakes of Black-throated Diver and probably more than } \\
30 \% \text { of the fishing lakes of Red-throated Diver, indicate } \\
\text { susceptibility of exposure to methylmercury. This find- } \\
\text { ing should be considered in relation to recent reports of } \\
\text { increased contents of mercury in freshwater fish. } \\
\text { Mats O. G. Eriksson, MK Natur-och Miljökonsult, } \\
\text { Tommeredsvägen 23, } 43792 \text { Lindome; } \\
\text { eriksson.tommered@telia.com } \\
\text { HeidiPaltto, Skövde högskola, Systembiologi, Box 408, } \\
\text { 54128 Skövde och Institutionen för Ekologi, Sveriges } \\
\text { Lantbruksuniversitet, Box } 7044,75007 \text { Uppsala; } \\
\text { Heidi.Paltto@ekol.slu.se }\end{array}$ \\
\hline
\end{tabular}

Received 12 May 2009, Accepted 8 December 2009, Editor: J. Waldenström

Storlommen Gavia arctica livnär sig till största delen på fisk och häckar främst vid näringsfattiga klarvattenssjöar med en i regel gles och artfattig fiskfauna. Ungarna matas företrädesvis med fisk, men även med vattenlevande insekter under de första levnadsveckorna, och bytena fångas vanligtvis i häckningssjöarna. I Sverige uppskattas det häckande beståndet till 5500-7000 par, och tillsammans med populationer i ungefär samma storleksordning i Finland och Norge återfinns över $95 \%$ av det europeiska beståndet (utanför Ryssland) i de nordiska länderna. Arten bedöms under de senaste 10-15 åren ha ökat i numerär i Sverige och Finland, medan den har minskat i Norge under samma period (BirdLife International 2004, Ottvall m.fl. 2008). Storlommens europeiska framtid är därför i hög grad beroende av hur de nordiska bestånden utvecklas. Ur det perspektivet kan en bättre förståelse av hur häckningsframgången varierar mellan olika sjöar med hänsyn till vattenkemi samt fiskbeståndens storlek och sammansättning vara av betydelse för inriktningen av vård- och skötselinsatser.

Syftet med den här studien är tvåfaldigt, dels att relatera storlommens häckningsutfall i ett antal sjöar spridda över landet till uppgifter om vattenkemi och fiskförekomst, dels att jämföra storlommens häckningssjöar och smålommens Gavia stellata fiskesjöar i dessa avseenden. Totalt omfattar undersökningen 122 storlomssjöar som inventerats inom ramen för arbetet i Projekt LOM (t.ex. Eriksson 2006a), och för smålomssjöarna har vi använt oss av data hämtade från en tidigare publicerad undersökning omfattande 34 fiskesjöar (Eriksson 2006b). Den kanske mest påtagliga skillnaden i de två lomarternas häckningsbiologi är att smålommen, till skillnad från storlommen, häckar vid små och ofta fisktomma skogstjärnar och myrgölar (oftast mindre än $1 \mathrm{ha}$ ), och att bytesfisk till ungarna hämtas i större klarvattenssjöar på upptill ett avstånd av 9-10 km från häckningstjärnen (t.ex. Eriksson 1994, Eriksson \& Johansson 1997).

Storlommens häckningsutfall har relaterats till olika egenskaper i häckningssjöarna också i tidigare undersökningar; t.ex. förekomsten av fisk (Eriksson 1986, 1987), sjöareal och förekomst av bebyggelse längs stränderna (Eriksson 1987, Er- 
iksson m.fl. 1995) samt vattenkemi (Eriksson \& Hake 2000). Alla dessa undersökningar bygger emellertid på uppgifter från ett färre antal sjöar än i den föreliggande studien och med en koncentration till landets sydvästra delar. Ingen av de tidigare studierna analyserar den sammantagna effekten av både fiskförekomst och vattenkemi.

Vattenkemin i lomsjöarna är av betydelse för bedömningar av risker förknippade med exponering av kvicksilver via födointaget, och i ett längre perspektiv kan klimatbetingade förändringar i de vattenkemiska förhållandena påverka lommarnas framtid. Dessa aspekter berörs avslutningsvis.

\section{Material och metoder}

\section{Urval av sjöar och antalet storlomspar som ingår $i$ undersökningen}

Urvalet har gjorts bland drygt 1800 sjöar där förekomst av minst ett stationärt (revirhållande) storlomspar har kunnat fastställas under minst ett år under perioden 1994-2008 genom rapporteringen till Projekt LOM samt kompletterande avstämningar mot rapporteringen till Artportalen/SVALAN, www.artportalen.se/birds/default.asp. Minimikravet för att ta med en sjö i undersökningen var att det fanns uppgifter om häckningsresultatet för minst fem år för åtminstone ett par som har uppehållit stadigvarande $\mathrm{i}$ sjön under häckningstid, eftersom detta bedömdes vara ett minimum för att kunna bedöma det genomsnittliga häckningsutfallet i sjön. Detta krav uppfylldes i 243 sjöar. Vidare skulle uppgifter om vattenkemiska förhållanden och/eller förekomsten av fisk finnas tillgängliga. Efter denna gallring återstod 122 sjöar (primärdata redovisas i appendix A).

Totalt representerar de 122 sjöarna bara $0,1 \%$ av landets över 95.700 sjöar som är större än $0,01 \mathrm{~km}^{2}$ (enligt SMHI 1996). Men bara en liten del av landets storlommar häckar i sjöar som är mindre än 0,1 $\mathrm{km}^{2}$ (tre sjöar i det undersökta materialet, appendix A), och därför är det mera relevant att relatera de återstående 119 sjöarna i undersökningen till landets drygt 24.000 sjöar som är större $0,1 \mathrm{~km}^{2}$, dvs. undersökningen omfattade $0,5 \%$ av dessa sjöar.

Antalet storlomspar som berördes av undersökningen har beräknats med ledning av rapporteringen till Projekt LOM. För sjöar där antalet rapporterade par har varierat mellan olika år har i regel medianvärdet använts (med justeringar för ett fåtal sjöar, appendix A). Totalt bedöms undersökningen ha omfattat 184 par eller 1,5 par per sjö, och svarande mot ungefär 3\% av det häckande beståndet i Sverige. Täckningen varierade emellertid mel- lan olika delar av landet; 113 par i Götaland och svarande mot ungefär $7 \%$ av storlomsbeståndet, 52 par eller 3\% av beståndet i Svealand och bara 19 par eller $0,7 \%$ av storlomsbeståndet i Norrland. Även om sjöarna inte har valts ut strikt slumpvis, torde de ge en representativ bild av de studerade förhållandena åtminstone i Götaland och Svealand, medan resultaten för Norrland kan ha påverkats av en överrepresentation av sjöar i Västernorrlands län (appendix A).

\section{Beräkning av häckningsresultatet.}

För varje sjö har ungproduktionen beräknats som medelantalet "stora" ungar per stationärt par och år för perioden 1994-2008, enligt tidigare beskrivna fältarbetsmetoder (t.ex. Eriksson \& Hake 2000, Hake m.fl. 2005). En bedömning av ungarnas överlevnad tills de blivit flygga gjordes genom att beräkna den genomsnittliga \%-andelen ungkullar med 2-3 stora ungar per år, och i dessa beräkningar ingår häckningar som inte upptäcktes förrän ungarna hade kläckts. Normalt lägger storlommen två ägg (ytterst sällan 3 ägg, 1-2\% av alla kullar enligt finska undersökningar; Lehtonen 1970), och i de flesta fall kläcks två ungar. Det är emellertid vanligt att bara ena ungen överlever till flygg ålder, och ungarnas överlevnad är till stor del avhängig av föräldrafåglarnas möjligheter att finna bytesfisk till ungarna (Jackson 2003, 2005). Andelen ungkullar med 2-3 stora ungar kan således ge en indikation på födosöksförhållandena i de olika fiskesjöarna. Primärdata redovisas i appendix A.

\section{Vattenkemi och ljusförhållanden i fiskesjöarna}

För information om vattenkemin har i första hand data från den nationella miljöövervakningens riksinventering av sjöar och vattendrag använts. Inom ramen för detta program har ett stort antal sjöar i landet undersökts från 1970-talet och framåt; i regel med fem års intervall men från 2007 ändrat till årliga provtagningar enligt ett rullande schema. Resultaten är tillgängliga via en databas vid Institutionen för miljöanalys vid Sveriges Lantbruksuniversitet (http://infol.ma.slu.se/db.html, se även Wilander m.fl. 2003 för metodik m.m.). Därutöver har kompletterande information erhållits för sjöar i Västra Götalands län. Genom att i huvudsak begränsa oss till den s.k. riksinventeringen har vi försäkrat oss om att vattenproverna har samlats in och analyserats med en konsekvent metodik.

Lommarna reagerar naturligtvis inte direkt på förändringar och variationer i sjöarnas vattenkemi, 
men olika vattenkemiska faktorer kan påverka förhållanden som är av betydelse för förekomsten i olika sjöar och för häckningsutfallet. Mot denna bakgrund har ungproduktionen i de olika sjöarna relaterats till följande parametrar:

- $p H$-värdet, som är ett mått på sjöns surhet. Flera av sjöarna var påverkade av försurning under mitten och slutet av 1900-talet, med utglesade fiskbestånd och ökat siktdjup som de mest påtagliga effekterna av betydelse för lommarnas födosök (t.ex. Eriksson 1991, 1994, Brodin 1995). Många av sjöarna är sedan 1980-talet föremål för kalkning, men man bör räkna med bestående ekologiska förändringar under lång tid även om pH-värdet efter kalkning legat på en högre nivå (t.ex. Appelberg 1995, Henrikson \& Brodin 1995)

- Alkalinitet, som är ett mått på sjöns buffertkapacitet eller förmåga att motstå surt nedfall.

- Totalfosforhalt, som är ett mått på sjöns näringsstatus och produktivitet.

- Absorbans, som är ett mått på genomsläppligheten av ljus i vattnet. Ljusförhållandena påverkas i första hand av humushalten och grumligheten. I den svenska miljöövervakningen används absorbansen av ljus vid våglängden $420 \mathrm{~nm}$ som ett standardiserat mått, och en för ögat påtaglig brunfärgning av vattnet upplevs vid en absorbans på ungefär $0,2 \mathrm{f}_{420 / 5}$.

- Siktdjup, som är ett alternativt mått på ljusförhållandena. Mätningar med siktdjupsskiva görs regelmässigt i samband med provfisken. Lommarna är s.k. visuella predatorer som lokaliserar sina byten med hjälp av synen, och i tidigare undersökningar har man funnit att siktförhållandena kan vara av stor betydelse för storlommens förekomst i olika sjöar (t. ex. Eriksson 1985, Eriksson \& Sundberg 1991, Kauppinen 1993). Det kan också vara värt att nämna att i samband med undersökningar av planktonförekomsten i mellansvenska sjöar på 1950-talet gjorde limnologen Bengt Pejler även noteringar av observerade fågelarter, och han noterade en tydlig koppling mellan näringsfattiga förhållanden, stort siktdjup och förekomsten av storlom (Pejler 1962).

Bedömning av de vattenkemiska förhållandena i fiskesjöarna har gjorts med ledning av de bedömningsgrunder som tillämpas av Naturvårdsverket (1999), på basis av medelvärdet för mätningarna 1995, 2000, 2005 och 2007 och med minimikravet att mätdata skall finnas tillgängliga för åtminstone två av de fyra åren (för siktdjup accepterades en mätning). Data fanns tillgängliga för 74 sjöar (58 sjöar vad gäller totalfosfor och 54 sjöar för siktdjup; primärdata återfinns i appendix $\mathrm{B}$, appendix D för siktdjup).

\section{Fiskbestånden i de undersökta sjöarna}

Bedömningar av antalet fiskarter och tätheten av fisk har gjorts med ledning av provfiskeresultat inom nationell och regional miljöövervakning, som finns samlade i databasen NORS (NatiOnellt Register för Sjöprovfisken, www.fiskeriverket.se, sök under statistik och databaser).

Information om antalet fiskarter bygger på provfisken under perioden 1979-2008, med uppgifter för totalt 80 häckningssjöar (primärdata i appendix C).

För bedömningar av fisktätheten har provfisken från perioden 1994-2008 använts, dvs. samma period som täcks av inventeringarna inom Projekt LOM. Materialet omfattar totalt 54 häckningssjöar (appendix D). Ett relativt mått på förekomsten har beräknats som medelantalet fiskar per nätansträngning, enligt de metoder som rekommenderas av Fiskeriverket (Kinnerbäck 2001). Skattningarna redovisas på basis av provfiske med bottennät, och inga justeringar har gjorts med hänsyn till eventuell nätselektivitet.

För beräkningarna av eventuella samband mellan fiskbeståndens täthet och ungproduktionen delades materialet upp med avseende på abborre Perca fluviatilis, mörtartad fisk, laxartad fisk, gers Gymnocephalus cernua, gädda Esox lucius och övriga fiskarter (se Tabell 2 eller Appendix C för sammanfattning av de fiskarter som redovisats under mörtartad och laxartad fisk samt övrig fisk). Uppdelningen betingades bland annat av att man i tidigare undersökningar noterat smålomsungarna $\mathrm{i}$ stor utsträckning matas med laxartad och mörtartad fisk (Eriksson m.fl. 1990), och att deras överlevnad är kopplad till förekomsten av dessa grupper i fiskesjöarna (Eriksson 2006b). Förekomst av gädda har i tidigare undersökningar påtalats som en negativ faktor för storlommen, med tanke på risken för predation av ungar (t.ex. Lehtonen 1970, Jackson 2003). Slutligen har man funnit att gers utgör en viktig del i dieten för smålommar som övervintrar i brackvattensmiljöer i Östersjön (Guse m.fl. 2006).

\section{Statistiska analyser}

Med hjälp av multipla linjära regressionsmodeller analyserade vi hur lommarnas häckningsutfall (dels medelantal ungar per par och år, dels andel ungkullar med 2-3 stora ungar) i de olika sjöarna 
Tabell 1. Vattenkemi och ljusförhållanden i häckningssjöar för storlom (data från appendix C och D) och (för jämförelse) fiskesjöar för smålom (data från Eriksson 2006b, Tabell 3 and appendix C).

Water chemistry and light conditions in the breeding lakes of Black-throated Diver (data from appendices $C$ and D) and (for comparison) fishing lakes for Red-throated Diver (data from Eriksson 2006b, Table 3 and appendix C).

A. Alla sjöar i de två undersökningarna. All lakes from both studies.

\begin{tabular}{|c|c|c|c|c|c|c|}
\hline & \multicolumn{3}{|c|}{$\begin{array}{c}\text { Häckningssjöar för storlom } \\
\text { Breeding lakes for } \\
\text { Black-throated Diver } \\
\end{array}$} & \multicolumn{3}{|c|}{$\begin{array}{l}\text { Fiskesjöar för smålom } \\
\text { Fishing lakes for } \\
\text { Red-throated Diver }\end{array}$} \\
\hline & $\begin{array}{l}\text { Medel } \\
\text { Mean }\end{array}$ & $\begin{array}{l}\text { Max-Min } \\
\text { Range }\end{array}$ & $\mathrm{N}$ & $\begin{array}{l}\text { Medel } \\
\text { Mean }\end{array}$ & $\begin{array}{l}\text { Max-Min } \\
\text { Range }\end{array}$ & $\mathrm{N}$ \\
\hline$\overline{\mathrm{pH}}$ & 6,9 & $6,1-8,0$ & 74 & 6,5 & $5,8-6,9$ & 20 \\
\hline $\begin{array}{l}\text { Alkalinitet, mekv/1 } \\
\text { Alkalinity, meq/l }\end{array}$ & 0,31 & $0,04-2,3$ & 74 & 0,11 & $0,03-0,20$ & 20 \\
\hline $\begin{array}{l}\text { Totalfosfor, mg/l } \\
\text { Total phosphorus, } \mathrm{mg} / \mathrm{l}\end{array}$ & 0,012 & $0,005-0,032$ & 58 & 0,010 & $0,005-0,019$ & 15 \\
\hline $\begin{array}{l}\text { Absorbans, } \mathrm{f}_{250 / 5} \\
\text { Absorbance, } f_{250 / 5}\end{array}$ & 0,11 & $0,03-0,39$ & 64 & 0,12 & $0,05-0,19$ & 19 \\
\hline $\begin{array}{l}\text { Siktdjup, m } \\
\text { Transparency, } m\end{array}$ & 3,7 & $0,8-10,5$ & 54 & 2,9 & $2,5-4,0$ & 7 \\
\hline
\end{tabular}

B. Fem sjöar som ingick både i undersökningen av smålommens fiskesjöar och i den föreliggande studien har uteslutits (not a). Dessutom har häckningssjöar för storlom i Skåne, Kalmar, Södermanlands, Stockholms och Uppsala län uteslutits eftersom smålom inte häckar i dessa län .

Five lakes included both in the study of fishing lakes of Red-throated Diver and in the present study have been exclude (note a). In addition, the breeding lakes of Black-throated Diver in the Counties of Skane, Kalmar, Södermanland, Stockholm and Uppsala have been excluded as Red-throated Diver does not breed in these counties ${ }^{b}$.

\begin{tabular}{|c|c|c|c|c|c|c|c|}
\hline & \multicolumn{3}{|c|}{$\begin{array}{l}\text { Häckningssjöar för storlom } \\
\text { Breeding lakes for } \\
\text { Black-throated Diver }\end{array}$} & \multicolumn{3}{|c|}{$\begin{array}{l}\text { Fiskesjöar för smålom } \\
\text { Fishing lakes for } \\
\text { Red-throated Diver }\end{array}$} & \multirow{2}{*}{$\begin{array}{c}\text { Mann- } \\
\text { Whitney } \\
\text { U-test, } \\
\text { tvåsidigt }^{\mathrm{b}} \text {, } \\
\text { two-tailed }^{b}\end{array}$} \\
\hline & $\begin{array}{l}\text { Medel } \\
\text { Mean }\end{array}$ & $\begin{array}{l}\text { Max-Min } \\
\text { Range }\end{array}$ & $\overline{\mathrm{N}}$ & $\begin{array}{l}\text { Medel } \\
\text { Mean }\end{array}$ & $\begin{array}{l}\text { Max-Min } \\
\text { Range }\end{array}$ & $\overline{\mathrm{N}}$ & \\
\hline$\overline{\mathrm{pH}}$ & 6,8 & $6,1-7,4$ & 52 & 6,4 & $5,8-6,9$ & 15 & $\mathrm{P}<0,001$ \\
\hline $\begin{array}{l}\text { Alkalinitet, mekv/l } \\
\text { Alkalinity, meq/l }\end{array}$ & 0,23 & $0,04-0,72$ & 52 & 0,11 & $0,03-0,20$ & 15 & $\mathrm{P}<0,001$ \\
\hline $\begin{array}{l}\text { Totalfosfor, mg/l } \\
\text { Total phosphorus, } \mathrm{mg} / \mathrm{l}\end{array}$ & 0,010 & $0,005-0,032$ & 37 & 0,010 & $0.005-0,019$ & 11 & $\begin{array}{l}\text { ej sign. } \\
N . S .\end{array}$ \\
\hline $\begin{array}{l}\text { Absorbans, } \mathrm{f}_{250 / 5} \\
\text { Absorbance, } f_{250 / 5}\end{array}$ & 0,11 & $0,03-0,39$ & 52 & 0,14 & $0,06-0,19$ & 14 & $\mathrm{P}=0,03$ \\
\hline $\begin{array}{l}\text { Siktdjup, } \mathrm{m} \\
\text { Transparency, } m\end{array}$ & 3,9 & $0,8-10,5$ & 37 & 2,9 & $2,5-4,0$ & 6 & $\begin{array}{l}\text { ej sign. } \\
N . S .\end{array}$ \\
\hline
\end{tabular}

a Fegen, Viaredssjön, Östra Nedsjön, Stora Le och Tisjön (detaljer i appendix A och B). Lakes Fegen, Viaredssjön, Östra Nedsjön, Stora Le and Tisjön (details in Appendices A and B).

b Resultatet blir likartat men P-värdena lägre om storlommens häckningssjöar i samtliga län innefattas i testen. The result will be similar but all P values are lower if breeding lakes for Black-throated Diver from all counties are included in the tests. 
påverkades av vattenkemiska variabler $(\mathrm{pH}$, alkalinitet, absorbans och totalfosforhalt) och fiskförekomst (abborre, mörtartad fisk, laxartad fisk, gers, gädda, övrig fisk samt siktdjup). Siktdjup ingick i fiskanalysen eftersom data insamlades vid provfisketillfället. En samlad analys av hur medelantalet ungar per par och år påverkades av både vattenkemiska variabler och fiskförekomst gjordes för 18 sjöar med kompletta data. Dessutom gjordes separata analyser av sambandet mellan fiskförekomst och medelantal ungar per par och år för 51 sjöar, samt sambandet mellan vattenkemiska variabler och medelantal ungar per par och år för 56 sjöar. För andelen ungkullar med 2-3 stora ungar gjordes ingen samlad analys innefattande både vattenkemi och fiskförekomst, eftersom båda typerna av data fanns tillgängliga för bara sex sjöar. Därför redovisas endast separata analyser för vattenkemi (21 sjöar) respektive fiskförekomst (12 sjöar) för andelen kullar med 2-3 stora ungar.

För alla analyser med fisk gjordes två parallella analyser; för hela fångsten respektive fiskar mindre än $22 \mathrm{~cm}$, eftersom storlomsungarna knappast kan hantera bytesfiskar av större storlek (t.ex. Jackson 2003, 2005).

För regressionsanalyserna användes funktionen "Im" i programmet R 2.8.1. (The foundation for statistical computing, 2008). En stegvis algoritm (kallas "step" i programmet; Hastie \& Pregiborn 1992, Faraway 2006, s. 21) användes för att stegvis minska antalet förklaringsvariabler och därmed minska modellens AIC (Akaike Information Criterion), som är ett mått på modellpassning (Burnham \& Anderson 2002). Förenklat kan man säga att AIC-måttet är ett index som optimerar modellen så att dess förklaringsgrad (ofta uttryckt som $\mathrm{R}^{2}$ ) blir så högt som möjligt under förutsättningen att modellen fortfarande förblir statistiskt signifikant. Parvisa korrelationsanalyser gjordes för att testa samvariationen mellan de ingående variablerna i analyserna. Alkalinitet var genomgående starkt korrelerad till $\mathrm{pH}$ (Spearman $\mathrm{r}=0,8)$, varför denna variabel uteslöts ur samtliga analyser. Övriga variabler som var starkt korrelerade till varandra togs med i modellen i ett första steg. Om båda variablerna återfanns i den reducerade modellen testades den reducerade modellen först utan den ena variabeln och sedan utan den andra variabeln. Endast modellen med lägst AIC-värde redovisas i resultatdelen.

\section{Jämförelser med smålommens fiskesjöar}

För jämförelser mellan storlomssjöarna och små- lommens fiskesjöar använde vi oss av uppgifter från den inledningsvis omnämnda undersökningen av smålommens fiskevatten (Eriksson 2006b); med uppgifter om de vattenkemiska förhållandena i 20 sjöar och med information om fiskbeståndens sammansättning i 18 sjöar. Fem sjöar (Fegen, Viaredssjön, Östra Nedsjön, Stora Le och Tisjön), som ingick både i smålomsstudien och i den föreliggande undersökningen av storlomssjöar uteslöts i de statistiska analyserna. Skillnader i sjöarnas egenskaper undersöktes med Mann-Whitney’s U-test.

\section{Resultat}

\section{Vattenkemi och ljusförhållanden}

Flertalet av sjöarna var näringsfattiga. Låga totalfosforhalter $(<0,013 \mathrm{mg} / \mathrm{l})$ noterades i ungefär två tredjedelar av dem, men bredden i näringsstatus var stor och $7 \%$ av sjöarna kunde bedömas som näringsrika (totalfosforhalt $>0,025 \mathrm{mg} / \mathrm{l}$ ). Näringsförhållandena var likartade i smålommens fiskevatten, med en totalfosforhalt på i medeltal $0,010 \mathrm{mg} / 1$ i både storloms- och smålomssjöarna (Tabell 1).

Ungefär $40 \%$ av sjöarna bedömdes som svagtmåttligt sura med $\mathrm{pH}$-värden mellan 6,2 och 6,8 , och $6 \%$ av dem var sura med $\mathrm{pH}$-värden under 6,2. Alkaliniteten var god i de flesta sjöarna, men $12 \%$ av dem hade en låg buffertkapacitet $(<0,10$ mekv/l). Både $\mathrm{pH}$-värden och alkalinitet var lägre i smålommens fiskesjöar, jämfört med storlomssjöarna; med pH-värden på i medeltal 6,4 resp. 6,8 och en genomsnittlig buffertkapacitet på 0,11 resp. 0,23 mekv/l (Tabell 1).

Med ledning av absorbansvärdena kan man sluta sig till att ungefär $70 \%$ av storlomssjöarna hade ett svagt-måttlig färgat vatten, och att $4 \%$ av dem var så starkt färgade att de torde ha haft en för ögat tydlig brunfärgning (absorbans $>0,2 \mathrm{f}_{250 / 5}$ ). $18 \%$ av sjöarna hade ett stort siktdjup $(>5,0 \mathrm{~m})$. Smålommens fiskesjöar hade genomgående mindre klart vatten än storlomssjöarna, med en genomsnittlig absorbans på 0,14 resp. $0,11 \mathrm{f}_{250 / 5}$ (Tabell 1 , primärdata i Appendix B och D).

\section{Fiskbeståndens artsammansättning}

Totalt noterades 26 fiskarter i de 80 storlomssjöarna med uppgifter om förekomsten av olika fiskarter (Tabell 2, primärdata i Appendix C). Artsammansättningen var den karakteristiska för näringsfattiga sjöar; med abborre, mört Rutilus rutilus och gädda i minst $90 \%$ av sjöarna. Laxartad fisk fanns i närmare hälften av de undersökta sjöarna; med sik Coregonus sp., siklöja Coregonus albula och nors 
Osmerus eperlanus som de mest spridda arterna. Ål Anguilla anguilla torde förekomma i betydligt fler än de två sjöar där den noterades, men arten fångas sällan med de provfiskemetoder som normalt används. Medelantalet fiskarter per sjö var 6,0 , men spännvidden var stor, från lågt artantal (1-2 arter) till över tio arter i en del sjöar (Figur 1).

Det genomsnittliga antalet fiskarter skiljde sig inte mellan storlommens häckningssjöar och smålommens fiskevatten, i medeltal 5,8 resp. 5,9 ar- ter på basis av data från 75 storlomssjöar och 14 smålomssjöar (Mann-Whitney U-test, ej sign.; de fem sjöarna som även ingick i den tidigare nämnda undersökningen av smålomssjöarna borttagna). Däremot fanns det en markant skillnad vad gäller förekomsten av laxartad fisk (Figur 1), som noterades i 13 av de 14 (93\%) smålomssjöarna men i bara $35(47 \%)$ av de 75 storlomssjöarna $\left(\chi^{2}=8,36\right.$, $\mathrm{df}=1, \mathrm{P}<0,01)$.

Tabell 2. Fiskarter i storlommens häckningssjöar (data i appendix C) och (för jämförelse) fiskesjöar för smålom (data från Eriksson 2006b, tabell 5 and appendix D).

Fish species in breeding lakes of Black-throated Diver (data from appendix $C$ ) and (for comparison) fishing lakes for Red-throated Diver (data from Eriksson 2006b, Table 5 and appendix D).

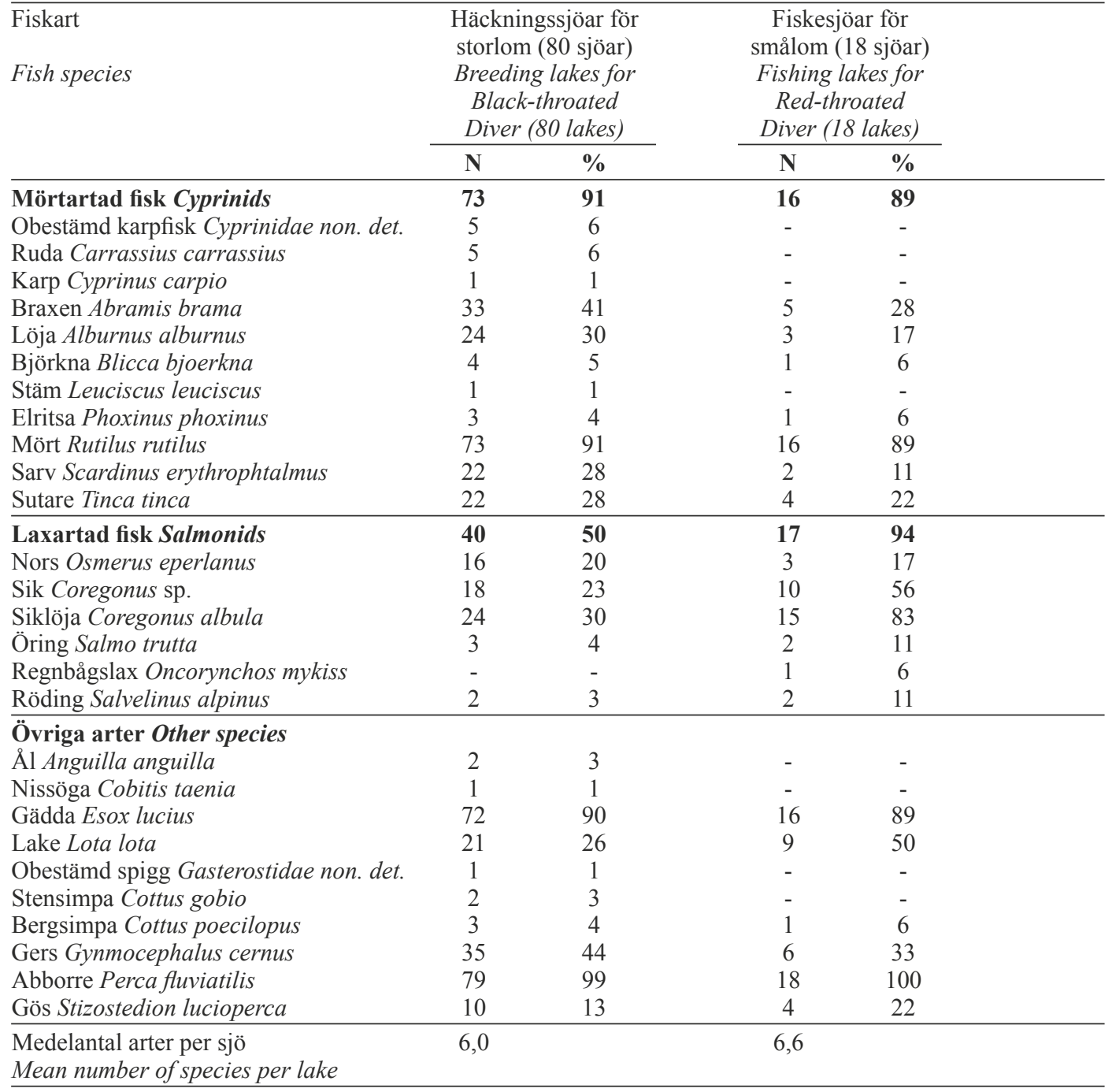




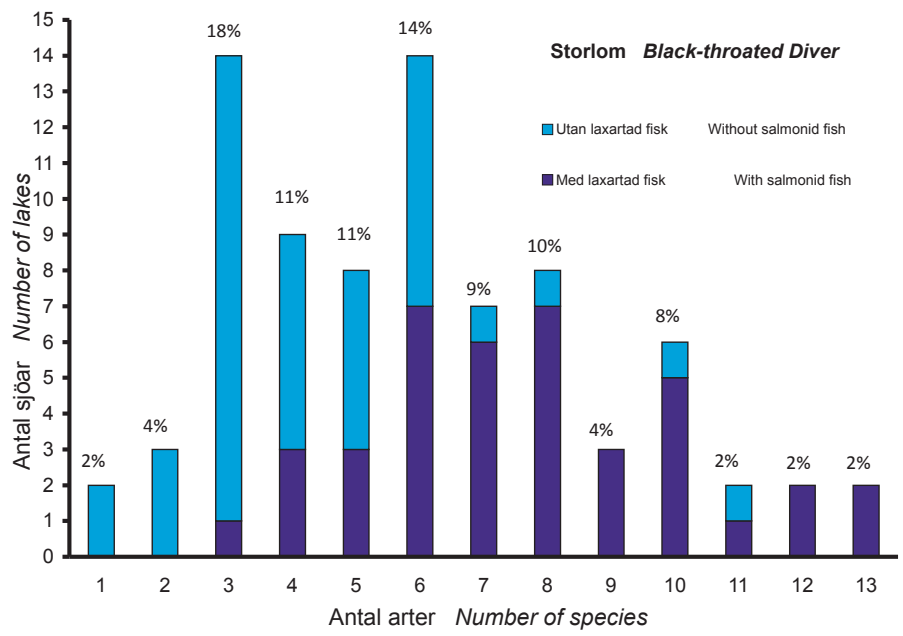

Figur 1. Fördelningen av häckningssjöar för storlom (data från appendix C) och fiskesjöar för smålom (data från Eriksson 2006b, appendix D) med avseende på antal arter och förekomsten av laxartad fisk.

The distribution of breeding lakes for Black-throated Diver (data from Appendix C) and fishing lakes for Redthroated Diver (data from Eriksson 2006b, Appendix D) with reference to number of species and the occurrence of salmonid fish.

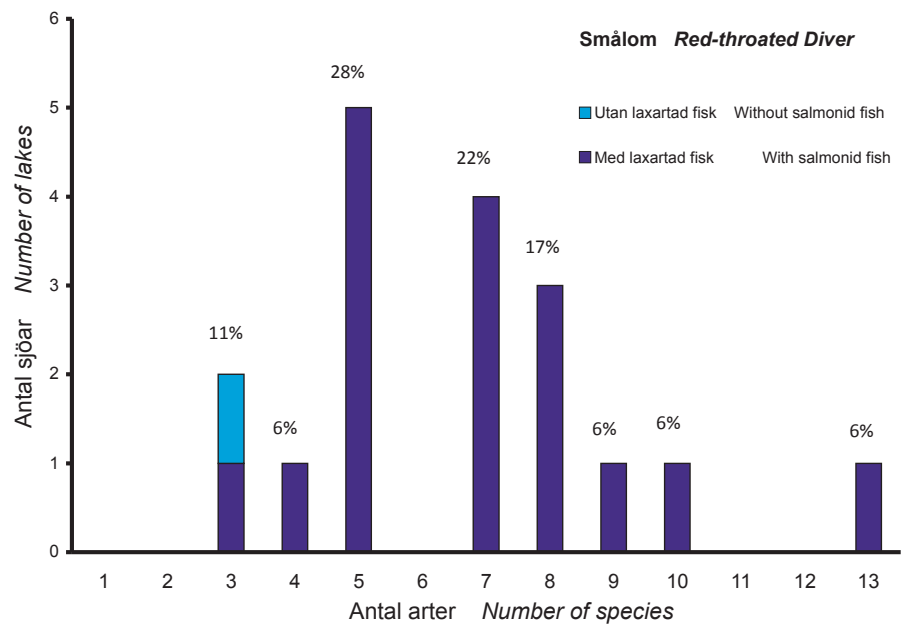

\section{Häckningsutfallet i relation till vattenkemi, ljusförhållanden och fiskförekomst}

Den sammanslagna regressionsmodellen omfattande 18 sjöar med information om såväl vattenkemi som fiskförekomst och siktdjup förklarade en avsevärd del av variationen i häckningsutfallet mellan de olika sjöarna (anpassat $\mathrm{R}^{2}=50 \%$ resp. $49 \%$ för totalfångsten av fisk resp., "småfisk" $<22 \mathrm{~cm}, \mathrm{P}=$ 0,027 i båda fallen, Tabell 3 samt Figur 2b, 2d, 2f). Sambandet var positivt för abborre och negativt för totalfosfor och siktdjup (Figur 2), och förklaringsgraden var ungefär densamma vare sig regressionsmodellen var baserad på totalfångsten av fisk eller "småfisk" $(<22 \mathrm{~cm})$ i den storlek som storlomsungarna kan hantera. Enkla regressionsanalyser mellan häckningsutfallet och de ovannämnda förklaringsvariablerna var inte statistiskt signifikanta (samband mellan häckningsutfall och abborre: $\mathrm{p}=0,073$, anpassat $\mathrm{R}^{2}=14 \%$; samband mellan häckningsutfall och fosforhalt respektive siktdjup: $p>0,200$, anpassat $\mathrm{R}^{2}=0 \%$; Figur 2a, 2c, 2e).

De multipla regressionsanalyserna avseende enbart vattenkemi (56 sjöar) respektive fisk (inkl. siktdjup, 51 sjöar) var inte signifikanta eller hade en avsevärt lägre förklaringsgrad.

Procentandelen ungkullar med 2-3 stora ungar var högre i sjöar med låga absorbansvärden, dvs. sjöar med förhållandevis klart vatten (Figur $3, \mathrm{R}^{2}=$ $26 \%$, regressionskoefficient $=-171,00 \pm$ S.E. 66,00 , $\mathrm{P}=0,018 ; 21$ sjöar, data från Appendix A och B). Däremot fanns det inte några indikationer på att 
Tabell 3. Utfallet av en multipel regressionsanalys av variationen i ungproduktionen (medelantalet stora ungar per par och år) i relation till vattenkemi, fiskförekomst och siktdjup i 18 häckningssjöar för storlom (data från appendix A, B och D).

The result of a multiple regression analysis of the variation in the production of young (mean number of large chicks per pair and year) in relation to water chemistry, occurrence of fish, and water transparency in 18 breeding lakes for Black-throated Diver (data from appendices A, B and D).

\begin{tabular}{|c|c|c|c|c|}
\hline Förklaringsvariabler Variables & $\begin{array}{l}\text { Anpassat } \\
\mathrm{R}^{2} \\
\text { Adjusted } \\
R^{2} \\
\end{array}$ & $\begin{array}{l}\mathrm{P} \text { (hela } \\
\text { modellen) } \\
P(\text { whole } \\
\text { model })\end{array}$ & $\begin{array}{l}\text { Regressions- } \\
\text { koefficient } \pm \text { S.E. }{ }^{\text {a }} \\
\text { Regression } \\
\text { coefficient } \pm \text { S.E.a }\end{array}$ & $\begin{array}{l}\mathrm{P} \text { (enskilda } \\
\text { variabler) } \\
P \text { (single } \\
\text { variables) }\end{array}$ \\
\hline $\begin{array}{l}\text { Total fiskfångst Total catch of fish } \\
\text { Abborre (medelantal per nätansträngning) } \\
\text { Perch (mean number per catch effort) }\end{array}$ & $50 \%$ & 0,027 & $0,023 \pm 0,006$ & 0,002 \\
\hline Totalfosfor Total phosphorus & & & $-0,038 \pm 0,008$ & 0,008 \\
\hline Siktdjup Water transparency & & & $-0,101 \pm 0,042$ & 0,035 \\
\hline $\begin{array}{l}\text { Laxartad fisk (medelantal per nätansträngning) } \\
\text { Salmonid fish (mean number per catch effort) }\end{array}$ & & & $0,080 \pm 0,050$ & 0,14 \\
\hline $\mathrm{pH}$ & & & $0,39 \pm 0,29$ & 0,20 \\
\hline Absorbans Absorbance & & & $-4,0 \pm 3,2$ & 0,25 \\
\hline $\begin{array}{l}\text { Fisk }<\mathbf{2 2} \mathbf{~ c m ~ F i s h ~}<\mathbf{2 2} \mathbf{~ c m ~} \\
\text { Totalfosfor Total phosphorus }\end{array}$ & $49 \%$ & 0,027 & $-0,035 \pm 0,012$ & 0,012 \\
\hline $\mathrm{pH}$ & & & $0,59 \pm 0,21$ & 0,017 \\
\hline $\begin{array}{l}\text { Abborre (medelantal per nätansträngning) } \\
\text { Perch (mean number per catch effort) }\end{array}$ & & & $0,019 \pm 0,008$ & 0,027 \\
\hline Siktdjup Water transparency & & & $-0,050 \pm 0,027$ & 0,091 \\
\hline $\begin{array}{l}\text { Gädda (medelantal per nätansträngning) } \\
\text { Pike (mean number per catch effort) }\end{array}$ & & & $4,1 \pm 2,7$ & 0,15 \\
\hline $\begin{array}{l}\text { Laxartad fisk (medelantal per nätansträngning) } \\
\text { Salmonid fish (mean number per catch effort) }\end{array}$ & & & $0,046 \pm 0,036$ & 0,22 \\
\hline
\end{tabular}

a Förväntad förändring i ungproduktionen per en enhets förändring i förklaringsvariabeln. Expected change in the production of young per one unit change of the variable.

procentandelen ungkullar med 2-3 stora ungar var kopplad till tätheten av fisk eller siktdjup (anpassat $\mathrm{R}^{2}=9 \%$, regressionskoefficient för siktdjup $=$ $0,174 \pm$ S.E. $6,2, \mathrm{P}=0,17 ; 12$ sjöar, primärdata i Appendix A och D).

\section{Diskussion}

Sammanfattande karakteristik av storlommens häckningssjöar

Storlommens häckningssjöar kan karakteriseras som näringsfattiga, oftast med ganska klart vatten. Ungefär en tiondel av sjöarna har en svag buffertkapacitet. Fisksamhällenas artsammansättning är typisk för näringsfattiga sjöar, även om antalet fiskarter kan variera från bara ett fåtal till över tio arter. Förekomsten av abborre är viktig för häckningsutfallet, medan ljusförhållandena är av betydelse för föräldrafåglarnas möjligheter att finna bytesfisk till ungarna och därmed indirekt för ungarnas överlevnad.

Förekomsten av ett negativt samband mellan sjöarnas näringsstatus (i den här undersökningen mätt som totalfosfor) och ungproduktionen var förväntad mot bakgrund av vad vi sedan tidigare känner till om storlommens förekomst i olika sjötyper (t.ex. Nilsson \& Nilsson 1978, Kauppinen 1993).

Det negativa sambandet mellan siktdjupet och 

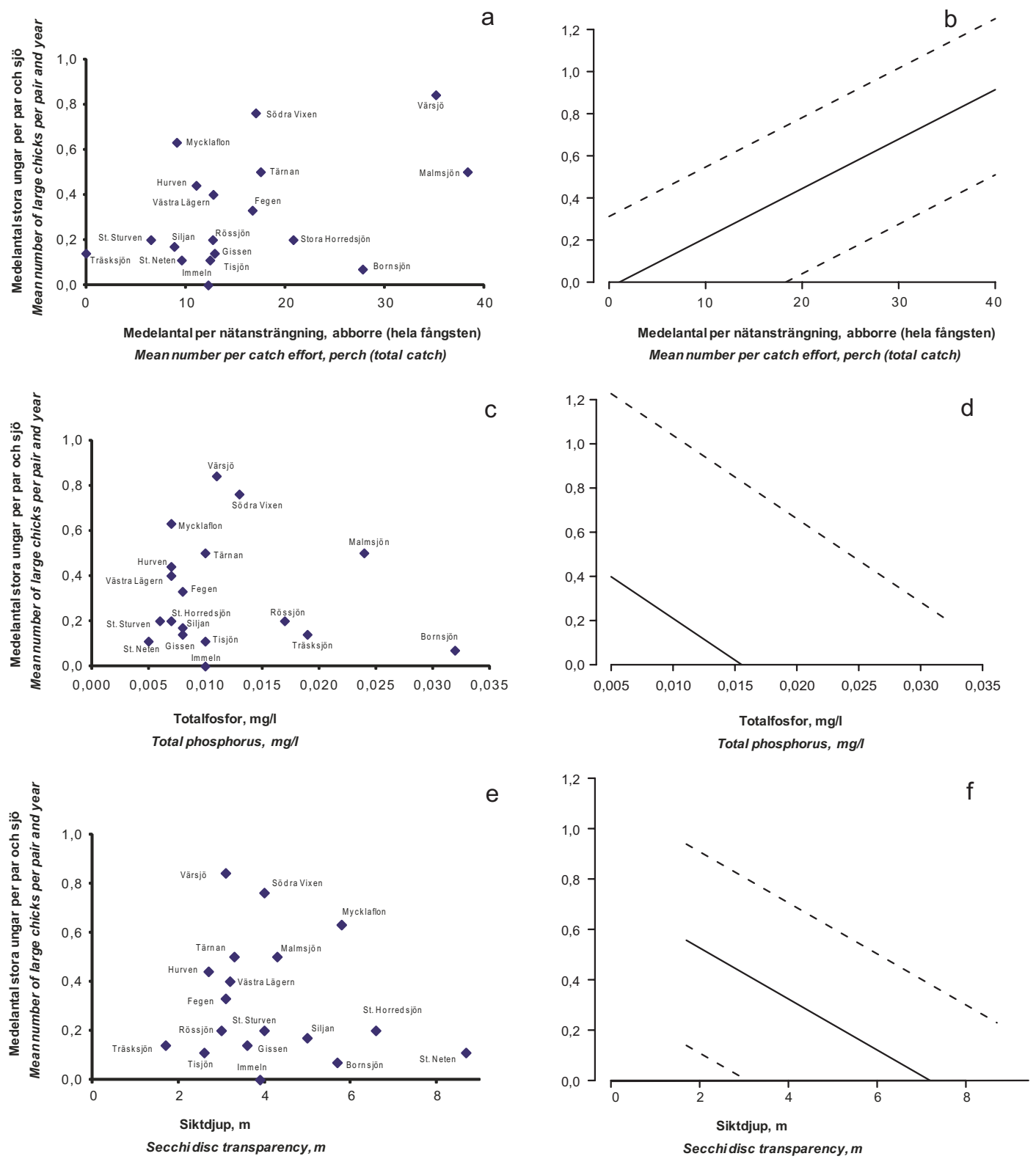

Figur 2. Medelantalet stora ungar per par och år i relation till totalfångsten av abborre (a, b), totalfosforhalt (c, d) och siktdjup (e, f) i 18 häckningssjöar för storlom (data från appendix A, C och D). Figurerna a, c, och e visar ett samband mellan medelantalet ungar och en förklaringsvariabel i taget utan hänsyn tagen till andra förklaringsvariabler. Figurerna b, $d$ och $f$ visar det förväntade medelantalet ungar vid förändring av en förklaringsvariabel, under förutsättning att de andra variablerna i modellen hålls konstanta (multipel linjär regression: Anpassat $\mathrm{R}^{2}=50 \%, \mathrm{P}=0,027$, se även Tabell 3). De heldragna linjerna visar medianvärdet av modellen för de 18 sjöarna och de streckade linjerna ett $95 \%$ konfidensintervall baserat på kvantiler, ett mått som hör ihop med medianvärden. De enkla sambanden är inte statistiskt signifikanta.

The mean number of large chicks per pair and year in relation to total catches of Perch (a, b), total phosphorus (c, d) and Secchi disc transparency (e, $f$ ) in 18 breeding lakes for Black-throated Diver (data from Appendices $A$, $C$ and $D)$. The figures $a, c$ and e show univariate relationships between the number of chicks and the environmental variable. The figures $b, d$ and $f$ show the predicted number of chicks as response to a change in one environmental variable, while holding the other environmental variables in the model constant (multiple linear regression model: Adjusted $R^{2}=50 \%, P=0.027$, see also Table 3). 


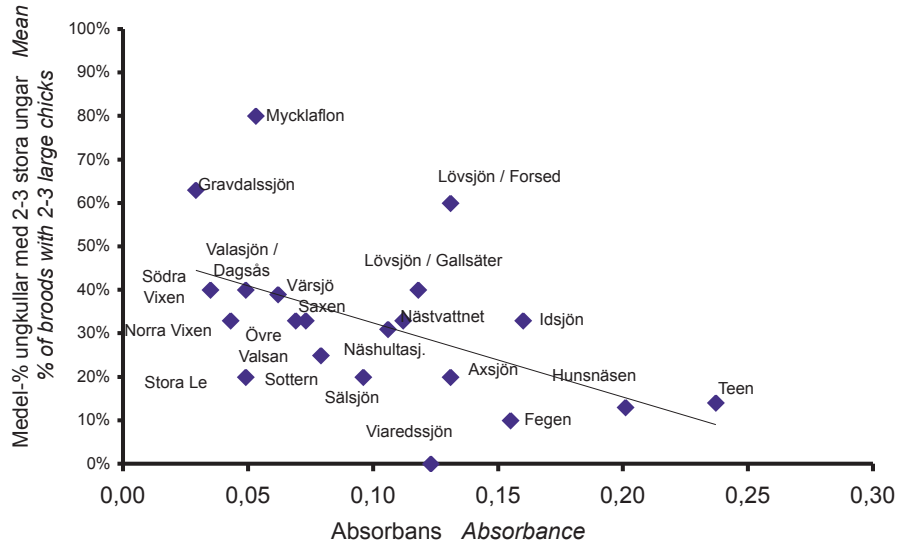

Figur 3. Procentandelen ungkullar med 2-3 stora ungar (medelvärde per år) i relation till absorbansen $\left(f_{250 / 5}\right)$ i 21 häckningssjöar för storlom (data från appendix A och B; multipel linjär regression: $\mathrm{R}^{2}=26 \%$, regressionskoefficient $=$ $-171,00 \pm$ S.E. $66,00, P=0,018)$. Linjär trendlinje inlagd.

The percentage of broods with 2-3 large chicks (mean per year) in relation to the absorbance $\left(f_{250 / 5}\right)$ in 21 breeding lakes for Black-throated Diver (data from appendices $A$ and $B$; multiple linear regression: $R^{2}=26 \%$, regressions coefficient $=-171.00 \pm$ S.E. 66.00, $P=0.018$ ). Linear trend line inserted. ungproduktionen (Tabell 3) var däremot oväntat, mot bakgrund av att man i tidigare undersökningar noterat att storlommen främst förekommer i sjöar med stort siktdjup. Även om ungarnas överlevnad är kopplad till goda ljusförhållanden (eller låg absorbans), torde ljusförhållandena likväl inte ha någon positiv påverkan på medelantalet stora ungar per par och år i de olika sjöarna, rimligtvis beroende på att huvuddelen av de misslyckade häckningarna avbryts redan under ruvningen (t.ex. Hake m.fl. 2005).

Predation på lomungarna från gädda, som i tidigare studier (Lehtonen 1970, Jackson 2003) utpekats som en riskfaktor, torde inte ha varit av så stor omfattning att det påverkat häckningsutfallet. Förekomsten av gädda tycks inte ha påverkat variationen mellan olika sjöar, vare sig med avseende på ungproduktionen eller på procentandelen ungkullar med 2-3 stora ungar.

Tätheten av abborre och sjöarnas vattenkemiska status förklarade hälften av den observerade variationen $\mathrm{i}$ ungproduktionen trots att endast 18 sjöar ingick i analysen. Anledningen till detta är förmodligen att både vattenkemiska variabler och fiskförekomst ingår i analysen, till skillnad från många tidigare studier som oftast har beaktat endast en av dessa aspekter åt gången. Att storlommens förekomst inte låter sig enkelt att förklaras av en enda miljöfaktor åt gången stöds av de enkla regressionsanalyserna där ingen av de tre signifikanta förklaringsvariablerna från den multipla regressionsanalysen var signifikanta var för sig. Den sammanlagda förklaringsgraden av de tre variablerna, när de testades var och för sig, var bara en tredjedel så stor, jämfört med förklaringsgraden i den multipla regressionsmodellen. Slutligen bör man hålla $\mathrm{i}$ minnet att den multipla regressions- modellen inte vägde in svårmätbara men förmodat viktiga variabler kopplade till problemfaktorer som identifierats i andra undersökningar, såsom vattenståndsvariationer, predation och störningar från friluftslivet (t.ex. Hake m.fl. 2005, Eriksson m.fl. 2005).

\section{Skillnader i storlommens och smålommens förekomst $i$ olika sjöar}

Även om flera av smålommens fiskesjöar också nyttjas av storlommen för häckning och födosök finns det skillnader i såväl sjöarnas vattenkemi och ljusförhållanden som fiskbeståndens sammansättning. Med viss grad av generalisering gäller att smålommen är bunden till ett smalare och mer "exklusivt" spektrum av sjöar än storlommen:

- Smålommens fiskesjöar har genomgående lägre pH-värden, sämre buffertkapacitet och mindre klart vatten (Tabell 1).

- Smålommen har en uttalad preferens för sjöar med laxartad fisk (bl.a. siklöja), vilket har påtalats i en rad undersökningar. Paul Rosenius uppmärksammade detta samband i sitt bokverk om "Svenska fåglar och fågelbon" som kom ut i flera band under början av 1900-talet och som byggde på en omfattande dokumentation av faunistisk information som fanns tillgänglig vid den tidpunkten (Rosenius 1942 vad gäller lommarna). Senare har kopplingen mellan smålomsförekomst och sjöar med goda bestånd av laxartad fisk noterats i inventeringar av regional eller lokal karaktär (t.ex. Andersson 1988, Borgström 1995), och detta förhållande har verifierats ytterligare i den här undersökningen (Figur 1).

- Smålomsungarnas överlevnad tills de blir flyg- 
ga är bland annat kopplad till förekomsten av småvuxen laxartad och mörtartad fisk i de sjöar där föräldrarna hämtar sin bytesfisk (Eriksson 2006b), medan ljusförhållandena och möjligheten för föräldrafåglarna att lokalisera fiskbytena tycks vara av större betydelse för en framgångsrik matning och storlomsungarnas överlevnad.

Det faktum att smålommens förekomst i olika sjöar inte är lika tydligt kopplat till ljusförhållandena har diskuterats av bl.a. Eriksson (1994, 2006b). Viktskillnaden mellan de två arterna är inte oväsentlig, och med ledning av handboksuppgifter kan man sluta sig till att en smålom väger ungefär 40\% mindre än en storlom (t.ex. Cramp \& Simmons 1977). Med hänvisning till att man inom andra grupper av fiskätande fåglar (t.ex. alkor) har funnit ett samband mellan kroppsvikten och dykningens längd hos olika arter (t.ex. Piatt \& Nettleship 1985, Wanless m.fl. 1988, Barrett \& Furness 1990), kan man således anta att den mindre och lättare smålommen inte har samma fördel som storlommen av att kunna lokalisera fiskbyten på större djup (som torde kräva längre dykningstider, t.ex. Boyd 1997). Detta kan kanske förklara varför smålommen är hänvisad till laxartad och mörtartad fisk, som uppträder pelagialt och nära vattenytan i större utsträckning än t.ex. abborre (Stenson 1979, Persson 1987).

\section{Avvikelser från "normen" vad gäller storlommens val av sjöar för häckning och födosök}

Även om det helt dominerande mönstret är att storlommen söker föda och matar ungarna med byten fångade i fiskesjön, kan arten uppvisa en viss flexibilitet och ibland söka föda i andra vattendrag än häckningssjön på "smålomsmanér". Exempelvis har utbyggnaden av de norrländska älvarna för vattenkraftsproduktion i många fall lett till att flodsträckorna ersatts med serier av vattenmagasin. I Skellefteälven har från 1960-talet och framåt stora bestånd av småvuxen sik etablerats i några av magasinen, och de utgör idag en viktig födobas för de lokala bestånden av både storlom och smålom. Variationerna i vattenståndet är emellertid så stora att storlommens häckningsförsök oftast misslyckas. Arten har i stället etablerat sig som häckfågel i kringliggande mindre sjöar, men bytesfisk till ungarna hämtas i stor utsträckning fortfarande i de reglerade vattenmagasinen. I några fall bedömdes storlommen ha drivit bort häckande knipor Bucephala clangula och vigg Aythya fuligula i de sjöar där den bosatt sig (Bildström 2006). Även i Norge har man noterat att storlommen ibland har etablerat sig vid små häckningssjöar (mindre än $0,10 \mathrm{~km}^{2}$ ) till följd av brist på boplatser vid större och ofta reglerade sjöar där de fortfarande hämtar bytesfisken till ungarna (Dunker \& Elgmork 1973).

I sydvästra Sverige har i några fall mycket goda häckningsresultat noterats för storlomspar häckande vid försurade sjöar där fiskbestånden minskat eller helt slagits ut. Man bedömde att lommarna till viss del kunnat kompensera bristen på bytesfisk genom ett ökat siktdjup (och därmed bättre möjlighet att lokalisera bytena) och att i större utsträckning mata ungarna med vattenlevande insekter, som ofta gynnas i frånvaron av predation från fisk (Eriksson 1986, 1991, 1994). Det finns också exempel på att bytesfisk hämtats från kringliggande sjöar, upptill åtminstone 3-4 km från häckningssjön (Ahlgren 1996).

\section{Storlommen i Skottland och en annorlunda sam- mansättning av fiskbestånden $i$ häckningssjöarna}

Skottland hyser närmare 200 storlomspar (BirdLife International 2004) som framförallt häckar i de nordvästra delarna. Storlommens förekomst och häckningsutfallet i olika sjöar visar i många stycken en annan bild än vad som gäller för svenska förhållanden. I en undersökning omfattande 90 sjöar (67 med uppgifter om häckande storlommar under perioden 1985-1994 samt 23 sjöar utan häckande storlommar, Jackson 2005) framgick bland annat att arten nästan uteslutande häckade vid sjöar med goda bestånd av småvuxen laxartad fisk, i huvudsak öring Salmo trutta, och att flertalet av de par som häckade vid sjöar utan laxartad fisk hämtade bytesfisk från närliggande sjöar med laxartad fisk. Elritsa Phoxinus phoxinus och storspigg Gasterosteus aculeatus förekom också i flera av undersökta sjöarna, och de utgjorde vid sidan av laxartad fisk en viktig del i storlomsungarnas diet. Abborre fanns bara i fem (6\%) och gädda i tolv (13\%) av de undersökta sjöarna. Gäddan är inte naturligt förekommande i Skottland men har satts ut i många sjöar, och fortsatt utplantering bedömdes som ett hot mot storlommen, både med hänsyn till risken för predation av små ungar (se även Lehtonen 1970) och konkurrens om bytesfisk.

Häckningsframgången var högre i sjöar där ungarnas i huvudsak kunde födas upp på fiskdiet, jämfört med sjöar där ungarna även matades med vattenlevande insekter (Jackson 2003, 2005). Den sjötyp där huvuddelen av de svenska storlomsparen återfinns, dvs. sjöar med dominans av abborre, mört och gädda, och där ungarna regelmässigt även matas med sländlarver och andra vattenlevande insekter under de första levnadsveckorna (Lehtonen 
1970, Sjölander 1978), är således ovanlig i Skottland och bedömdes i de skotska undersökningarna som en suboptimal storlomsmiljö.

\section{Fiske- och vattenvård i storlommens häckningssjöar och smålommens fiskevatten}

Många lomsjöar har en naturligt låg alkalinitet och de har i stor utsträckning varit påverkade av försurning under mitten och slutet av 1900-talet, med utglesade eller helt utslagna fiskbestånd som följd (t.ex. Eriksson 1991, 1994). Som tidigare nämnts har flera av sjöarna varit föremål för fortlöpande kalkningsinsatser med syftet att återskapa och vidmakthålla gynnsamma livsbetingelser för fisk efter påverkan av sur nederbörd. Även om man under de senaste åren har inlett en utfasning av kalkningsverksamheten bedömer man att fortsatta insatser under ytterligare ett antal årtionden är nödvändiga i många försurningspåverkade sjöar för att vidmakthålla de ofta goda resultat som erhållits vad gäller den ekologiska återhämtningen (t.ex. Henrikson \& Brodin 1995, Warfwinge \& Bertills 2000). Med avseende på fågelskyddet bör i första hand smålommens fiskevatten prioriteras, men även storlommens häckningssjöar kan komma ifråga, i den fortsatta kalkningsverksamheten och vid risk för återförsurning (se även Eriksson 2006b). Man bör emellertid undvika att utföra själva kalkningsarbetet under häckningstid för att undvika störningar av såväl häckande lommar som andra sjöfågelarter. Man bör inte heller kalka i smålommens häckningstjärnar, med tanke på risken för påverkan på kringliggande myrvegetation och boplatserna kvalitet.

\section{Kvicksilverbelastning och de vattenkemiska förhållandena i lomsjöarna}

Lommarna befinner sig slutändan av en näringskedja med flera mellanled, från primärproducenterna $i$ form av växter och växtplankton via djurplankton och vattenlevande insekter till den fisk som lommarna livnär sig på. Man kan alltså utifrån generella kunskaper om hur giftiga ämnen ackumuleras i näringskedjorna förvänta sig att lommarna är sårbara för exponering av miljögifter. Allmänt anser man för fiskätande fåglar i sötvattensmiljöer att det är tungmetaller, och i första hand kvicksilver som bör beaktas, bland annat mot bakgrund av att kvicksilvret i fisk nästan bara uppträder i form av metylerade föreningar (t.ex. Scheuhammer 1991). Gifteffekterna tar sig uttryck i försämrad fortplantning, och vid högre belastning neurologiska stör- ningar och beteenderubbningar. Hos adulta fåglar riskerar man störningar i fortplantningen i koncentrationer som är ungefär $20 \%$ av de som krävs för att beteendeförändringar skall uppstå (t.ex. Scheuhammer 1987).

Det finns emellertid få jämförande studier av hur olika fågelarter påverkas av exponeringen av kvicksilver i nordiska sötvattensmiljöer. På 1970-talet undersöktes spridningen av miljögifter i Finlands näst största sjö, Päijänne, och man analyserade bland annat halterna i muskel- och leverprover från ett 10-tal fågelarter (Särkkä m.fl. 1978). Fiskätande fåglars sårbarhet demonstrerades tydligt genom att kvicksilverinnehållet i prover från storlom och storskrake Mergus merganser låg långt över de nivåer som uppmättes för övriga arter. Analyser av lomägg insamlade på skilda håll i Sverige under 1980- och 1990-talen visade på generellt högre halter av kvicksilver i ägg från smålom jämfört med storlom (i enstaka fall med mycket höga värden där reproduktionsstörningar inte kan uteslutas). Halterna i storlomsägg insamlade vid sjöar påverkade av försurning var genomgående högre än i andra sjöar (Eriksson \& Lindberg 2005).

I den enskilda sjön påverkas kvicksilverinnehållet i fisk på ett ganska komplicerat sätt av såväl vattenkemin som markförhållandena och markanvändningen i tillrinningsområdet. Under det senaste årtiondet har frågor om läckage till grundoch ytvatten av kvicksilver som deponerats från atmosfäriskt nedfall i skogs- och myrmark, fătt ökad uppmärksamhet. Under denna transport omvandlas oorganiskt kvicksilver till fettlösligt och därmed biotillgängligt metylkvicksilver (t.ex. Skyllberg 2003, Evers m.fl. 2007). I Sverige har frågan aktualiserats i samband med rapporter om att kvicksilverhalterna i insjöfisk åter har stigit under senare år efter en lång tids nedåtgående trend från 1960-talet fram till 1990-talet ( $\AA$ kerblom \& Johansson 2008).

Riskerna för exponering av kvicksilver för vattenlevande organismer är nära knuten till de vattenkemiska förhållandena. På basis av undersökningar i nordöstra USA har man bedömt att riskerna för bioackumulering av metylerat kvicksilver är störst i lågproduktiva sjöar; med totalfosforhalt lägre än $0,03 \mathrm{mg} / \mathrm{l}$ i kombination med $\mathrm{pH}$-värde under 6,0, alkalinitet under $0,10 \mathrm{mekv} / \mathrm{l}$ eller en halt på löst organiskt kol (DOC) över $4 \mathrm{mg} / \mathrm{l}$ som riktvärden för vattenkvalitén i sjöar i riskzonen (Driscoll m.fl. 2007).

Huvuddelen av de häckningssjöar för storlom som omfattas av den föreliggande studien hade en totalfosforhalt lägre eller i nivå med gränsvärdet på $0,03 \mathrm{mg} / 1$ ( 56 av totalt 58 sjöar med information om 
totalfosfor, appendix B), och för alla de undersökta fiskesjöarna för smålom (Tabell 1) låg totalfosforhalterna under detta gränsvärde. Det finns således anledning att anta att huvuddelen av de undersökta sjöarna ligger i riskzonen för en ökad exponering för kvicksilver som kan spåras till atmosfäriskt nedfall, om de samtidigt är sura eller har en svag buffertkapacitet. I alla de undersökta häckningssjöarna för storlom låg $\mathrm{pH}$-värdet över det ovannämnda gränsvärdet på 6,0 (Tabell 1, appendix B) men för sju av sjöarna (närmare $10 \%$ ) registrerades en alkalinitet under gränsvärdet på $0,10 \mathrm{mekv} / \mathrm{l}$ (data från appendix B). För smålommens fiskesjöar noterades $\mathrm{pH}$-värden under 6,0 i två $(10 \%)$ av 20 undersökta sjöar och sju (35\%) av sjöarna hade en alkalinitet under 0,10 mekv/l (primärdata från Eriksson 2006b, appendix C). Förutsatt att dessa resultat kan generaliseras gäller således för närmare $10 \%$ av landets häckningssjöar för storlom och kanske mer än $30 \%$ av fiskesjöarna för smålom att de är sårbara för en ökad exponering för kvicksilver som deponerats i skogs- och myrmark och därefter urlakats till grund- och ytvatten och samtidigt metylerats.

Huvuddelen av det kvicksilver som numera påverkar sjöar och vattendrag kan härledas till förbränning av fossila bränslen. Ansträngningar för att minska beroendet och förbrukningen av olja av klimatpolitiska skäl torde alltså på sikt också kunna bidra till en minskad exponering för kvicksilver för lommar och andra toppredatorer i sötvattensmiljöer. Utfallet av nordamerikanska modelleringsstudier visar att även begränsningar av lokala utsläpp kan ge positiva effekter (Evers m.fl. 2007).

\section{Klimatbetingade förändringar i lomsjöarna}

I ett långsiktigt perspektiv kan frågor om hur lommarna påverkas av framtida klimatförändringar inte undvikas. I prognoser över den europeiska fågelfaunans långsiktiga utveckling har man för flera arter med sin huvudsakliga utbredning i norra Europa förutspått att häckningsområdet kommer att krympa genom att sydgränsen förskjuts ytterligare norrut. Om prognoserna slår in kan både storlommen och smålommen vara försvunna som häckfåglar i landets södra och mellersta delar, liksom från större delen av Finland, på 2090-talet (Huntley m.fl. 2007).

Sett till hur lomsjöarna kan komma att förändras är det ganska enkelt förutse att faktorer som är viktiga för lommarna, såsom fiskförekomst och siktförhållanden kommer att påverkas. Effekterna är emellertid extremt svåra att förutsäga mera i de- talj i den typ av näringsfattiga sjöar där lommarna i första hand förekommer (t.ex. Nordiska Ministerrådet 2005) och i hög grad beroende på utfallet av den samlade påverkan av bland annat kortare isläggningsperioder, högre vattentemperaturer och ändrade språngskiktsförhållanden. En längre växtsäsong kan gynna makrofytfloran, med bibehållna ljusförhållanden och en måttlig förändring i näringsstatus som följd. Alternativt kan förändringarna ge upphov till en ökad produktion av alger och en utveckling mot mer näringsrika förhållanden och förhöjda halter av organiskt lösta ämnen, med åtföljande försämrade ljusförhållanden. Detta kan i sin tur leda till förändringar i fisksamhällenas sammansättning, med en utveckling som missgynnar bland annat abborre och gädda men gynnar olika arter av mörtartad fisk. I sjöar som utvecklas i denna riktning kan man påräkna påtagligt förändrade förutsättningar för lommarna.

I det långsiktiga fågelskyddsarbetet avseende lommarna måste man alltså beakta risken för förändringar i sjöarnas näringsstatus och ljusförhållanden som gör dem mindre attraktiva eller lämpliga för häckning och födosök. Ett framtida arbete som syftar till att bibehålla eller återskapa goda betingelser för lommarna såväl som deras bytesfisk bör vara en långsiktig utmaning både för fågelskyddsarbetet och för fiskevården under de kommande årtiondena, lämpligen inom ramen för en nationell eller europeisk strategi som är väl förankrad inom olika intressegrupper.

\section{Tack}

Undersökningen har genomförts inom ramen för Projekt LOM, som under perioden 1994-1999 drevs gemensamt av Svenska Naturskyddsföreningen och Sveriges Ornitologiska Förening och därefter som en fristående ideell förening. Uppgifterna om lommarnas häckningsresultat i de undersökta sjöarna har samlats in genom ett omfattande fältarbete. Ungefär ett 70-tal personer har på frivillig och ideell basis medverkat med uppgifter om lommarnas häckning i de undersökta sjöarna, ofta genom upprepade insatser under flera år. Utan deras samlade insats hade det inte varit möjligt att genomföra den här studien.

Ekonomiskt stöd för arbetet med att relatera uppgifter om vattenkemiska förhållanden och fiskeförekomst till lommarnas häckningsutfall har erhållits från Naturvårdsverket, inom ramen för ett bidrag som verket utbetalat till Sveriges Ornitologiska Förening för att redovisa och utvärdera arbetet inom Projekt LOM. Bidrag har även erhållits 
från Alvins Fond, Världsnaturfonden-WWF och Bingolotto-Återvinsten.

Uppgifter om vattenkemiska förhållanden har i första hand hämtats från den nationella miljöövervakningens riksinventering av sjöar och vattendrag via hemsidan för Institutionen för miljöanalys vid Sveriges Lantbruksuniversitet (http://info1.ma.slu. se/db.html), och information om fiskbestånden i de undersökta sjöarna har i främst erhållits via Fiskeriverkets provfiskedatabas (http://www.fiskeriverket.se). Därutöver har Dan Hellman bidragit med uppgifter om vattenkemi i Västra Götalands län. Vikki Bengtsson har granskat de engelskspråkiga textavsnitten. Börje Ekstam har gett värdefulla synpunkter som förbättrat innehållet i uppsatsen.

\section{Referenser}

Ahlgren, C.-G. 1996. Kroksjö - den perfekta storlomssjön?! Fåglar i Södra Älvsborg 22: 42-44.

Andersson, M. 1988. Smålommen i Västmanland. Fåglar $i$ Västmanland 19: 85-93.

Appelberg, M. 1995. The impact of liming on aquatic communities. Sid. 283-203 i Henrikson, L. \& Brodin, Y.-W., red. Liming of acidified surface waters - a Swedish synthesis. Springer, Berlin.

Barrett, R.T. \& Furness, R.W. 1990. The prey and diving depths of seabirds on Hornøy, North Norway after a decline on the Barents Sea capelin stocks. Ornis Scandinavica 21: 179-186.

Bildström, L. 2006. Storlommens aggression mot dykänder vid häckplatser kring Skellefteälven, södra Lappland. Ornis Svecica 16: 232-235.

BirdLife International. 2004. Birds in Europe: population estimates, trends and conservation status. BirdLife International, Cambridge (BirdLife Conservation Series No. 12).

Borgström, E. 1995. Smålommen i Hagfors kommun 1995. Värmlandsornitologen 24: 45-50.

Boyd, I.L. 1997. The behavioural and physiological ecology of diving. Trends in Ecology and Evolution 12: 213-217.

Brodin, Y.-W. 1995. Acidification of Swedish freshwaters. Sid. 63-80 i Henrikson, L. \& Brodin, Y.-W., red. Liming of acidified surface waters - a Swedish synthesis. Springer, Berlin.

Burnham, K.P. \& Anderson, D.R. 2002. Model selection and multimodel inference: A practical information-theoretic approach. Second edition. Springer-Verlag, New York, USA.

Cramp, S. \& Simmons, K.E.L. 1977. Handbook of the birds of Europe, the Middle East, and North Africa: the birds of the Western Palearctic. Volume 1. Oxford University Press, Oxford.

Driscoll, C.T., Young-Ji, H., Chen, C., Evers, D., Lambert, K.F., Holsen, T.M., Kamman, N.C. \& Munson, R.K. 2007. Mercury contamination in forest and freshwater ecosystems in northeastern United States. Bioscience 27: 17-28.

Dunker, H. \& Elgmork. K. 1973. Nesting of the Blackthroated Diver, Gavia arctica (L.) in small bodies of wa- ter. Norw. J. Zool. 21: 33-37.

Eriksson, M.O.G. 1985. Prey detectability for fish-eating birds in relation to fish density and water transparency. Ornis Scandinavica 16: 1-7.

Eriksson, M.O.G. 1986. Reproduction of Black-throated Diver Gavia arctica in relation to fish density in oligotrophic lakes in southwestern Sweden. Ornis Scandinavica 17: 245-248.

Eriksson, M.O.G. 1987. Storlommens Gavia arctica produktion av ungar i sydvästsvenska sjöar. Vår Fågelvärld 46: 172-186.

Eriksson, M.O.G. 1991. Försurningspåverkan på fågel- och däggdjursbestånd. Naturvårdsverket rapport 3969.

Eriksson, M.O.G. 1994. Susceptibility to freshwater acidification by two species of loon: Red-throated Loon (Gavia stellata) and Arctic Loon (Gavia arctica) in southwest Sweden. Hydrobiologia 279-280: 439-444.

Eriksson, M.O.G. 2006a. Projekt Lom 2004-05. Sid. 51-57 i SOF red. Fågelåret 2005, Sveriges Ornitologiska Förening, Stockholm.

Eriksson, M.O.G. 2006b. Smålommens Gavia stellata häckningsframgång i relation till vattenkemi och fiskbeståndens sammansättning i olika fiskevatten. Ornis Svecica 16: $211-231$.

Eriksson, M.O.G., Ahlgren, C-G., Fallberg, R., Karlsson, G. \& Kongbäck, H. 1995. Storlommens (Gavia arctica) häckningsframgång i sydvästra Sverige 1982-1992. Ornis Svecica 5: 1-14.

Eriksson, M.O.G., Blomqvist, D., Hake, M. \& Johansson, O. 1990. Parental feeding in the Red-throated Diver Gavia stellata. Ibis 132: 1-13.

Eriksson, M.O.G., Dahlgren, T., Holmer, A., Lindberg, P. \& Åhlund, M. 2005. Storlommens Gavia arctica häckningsframgång innanför och utanför fågelskyddsområden i sjöarna Fegen och Sottern. Ornis Svecica 15: 212-219.

Eriksson, M.O.G. \& Hake, M. 2000. Storlommens Gavia arctica häckningsframgång i relation till vattenkemi, försurning, kvicksilverhalt i fisk och sjöyta i sydsvenska sjöar. Ornis Svecica 10: 95-105.

Eriksson, M.O.G. \& Johansson, I. 1997. Smålommen Gavia stellata i sydvästra Sverige - beståndsutveckling och häckningsframgång. Ornis Svecica 7: 1-10.

Eriksson, M.O.G. \& Lindberg, P. 2005. Kvicksilverbelastningen hos svenska smålommar Gavia stellata och storlommar Gavia arctica. Ornis Svecica 15: 1-12.

Eriksson, M.O.G. \& Sundberg, P. 1991. The choice of fishing lakes by Red-throated Diver Gavia stellata and Blackthroated Diver G. arctica during the breeding season in south-west Sweden. Bird Study 38: 153-144.

Evers, D.C., Hart, Y.-J., Driscoll, C.T., Kamman, N.C., Goodale, M.W., Lambert, K.F., Holsen, T.M., Chen, C., Clair, T.A. \& Butler, T. 2007. Biological mercury hotspots in northeastern United States and southeastern Canada. Bioscience 27: 29-43.

Faraway, J. 2006. Extending the linear model with R-Generalized linear, mixed effects and non-parametric regression models. Chapman \& Hall/CRC, London,

Guse, N., Garthe, S., Mundry, R. \& Schirmeister, B. 2006. Seasonal variation in the diet of the red-throated diver (Gavia stellata) in the Pomeranian Bight, Baltic Sea. "Poster" vid $24^{\text {th }}$ International Ornithological Congress, Hamburg, 13-19 August 2006.

Hake, M., Dahlgren, T., Åhlund, M., Lindberg, P. \& Eriks- 
son, M.O.G. 2005. The impact of water-level fluctuation on the breeding success of Black-throated Diver Gavia arctica in South-west Sweden. Ornis Fennica 82: 1-12.

Hastie, T. J. \& Pregibon, D. 1992. Generalized linear models. Kapitel 6 i J. Chambers, M. \& T. J. Hastie, T.J. (red.). Statistical Models in S. Wadsworth \& Brooks/Cole, Pacific Grove.

Henrikson, L. \& Brodin, Y.-W. 1995. Liming surface waters in Sweden. Sid 1-44 i Henrikson, L. \& Brodin, Y.-W. red. Liming of acidified surface waters - a Swedish synthesis. Springer, Berlin.

Huntley, B., Green, R.E., Collingham, Y. \& Willis, S.G. 2007. A climatic atlas of European breeding birds. Durham University, The RSPB och Lynx Editions, Barcelona.

Jackson, D. 2003. Between lake differences in the diet and provisioning behaviour of Black-throated Divers Gavia arctica breeding in Scotland. Ibis 145: 30-44.

Jackson, D.J. 2005. Environmental correlates of lake occupancy and chick survival of Black-throated Divers $G a$ via arctica in Scotland. Bird Study 52: 225-236.

Kauppinen, J. 1993. Densities and habitat distribution of breeding waterfowl in boreal lakes in Finland. Finnish Game Research 48: 24-45.

Kinnerbäck, A. 2001. Standardiserad metodik för provfiske i sjöar. Fiskeriverket informerar 2001:2. (även tillgänglig via Fiskeriverkets hemsida, http://www.fiskeriverket).

Lehtonen, L. 1970. Zur Biologie des Prachttauchers, Gavia a. $\operatorname{arctica}(\mathrm{L}$.$) . Ann. Zool. Fennici 7: 25-60.$

Naturvårdsverket 1999. Bedömningsgrunder för miljökvalitet - sjöar och vattendrag. Naturvårdsverket rapport 4913 .

Nilsson, S.G. \& Nilsson, I.N. 1978. Breeding bird community densities and species richness in lakes. Oikos 31: 214-221.

Nordiska Ministerrådet 2005. Conservation of Nordic nature in a changing climate. TemaNord 2005:572.

Ottvall, R., Edenius, L., Elmberg, J., Engström, H., Green, M., Holmqvist, N., Lindström, Å., Tjernberg, M. \& Pärt, T. 2008. Populationstrender för fågelarter som häckar i Sverige. Naturvårdsverket Rapport 5813.

Pejler, B. 1962. Om sjöfåglar och sjötyper. Vår Fågelvärld 21: 267-274.

Persson, L. 1987. Effects of habitat and season on competitive interactions between roach (Rutilus rutilus) and perch (Perca fluviatilis). Oecologia (Berl.) 73: 170-177.

Piatt, J.F. \& Nettleship, D.N. 1985. Diving depths of four alcids. Auk 102: 293-297.

Rosenius, P. 1942. Sveriges fåglar och fågelbon. Femte bandet. Gleerups, Lund.

Scheuhammer, A.M. 1987. The chronic toxicity of aluminium, cadmium, mercury and lead in birds: a review. Environmental Pollution 46: 263-295.

Scheuhammer, A.M. 1991. Effects of acidification on the availability of toxic metals and calcium to wild birds and mammals. Environmental Pollution 71: 329-375.

Sjölander, S. 1978. Reproductive behaviour of Black-throated Diver Gavia arctica. Ornis Scandinavica 9: 51-65.

Skyllberg, U. 2003. Kvicksilver och metylkvicksilver i mark och vatten - bindning till humus avgörande för miljörisk. Fakta Skog, nr 11, 2003.

SMHI 1996. Svenskt sjöregister, volym 1(2) och 2(2). SMHI Hydrologi, $\mathrm{nr} 71$.

Stenson, J.A.E. 1979. Predator-prey relationships between fish and invertebrate prey in some forest lakes. Rep. Inst.
Freshw. Res. Drottningholm 58: 166-183.

Särkkä, J., Hattula, M.-L., Janatuinen, J., Paasivirta, J. \& Palokangas, R. 1978, Chlorinated hydrocarbons and mercury in birds of Lake Päijänne, Finland - 1972-74. Pesticides Monitoring Journal 12: 26-35.

Wanless, S., Morris, J.A. \& Harris, M.P. 1988. Diving behaviour of guillemot Uria aalge, puffin Fratercula arctica and razorbill Alca torda as shown by radio-telemetry. $J$. Zool. Lond. 216: 73-81.

Warfvinge, P. \& Bertills, U. red., 2000. Naturens återhämtning från försurning - aktuell kunskap och framtidsscenarier. Naturvårdsverket Rapport 5028.

Wilander, A., Johnson, R.K. \& Goedkoop, W. 2003. Riksinventering 2003 - en synoptisk studie i vattenkemi och bottenfauna i svenska sjöar och vattendrag. Inst. för miljöanalys, SLU, rapport 2003:1.

Åkerblom, S. \& Johansson, K. 2008. Kvicksilver i svensk insjöfisk - variationer i tid och rum. SLU, Inst. för miljöanalys, SLU rapport 2008:8.

\section{Hemsidor}

http://www.artportalen.se/birds/default.asp: Artportalen/SVALAN.

http://www.fiskeriverket.se:

Fiskeriverkets provfiskedatabas, sök under statistik och databaser.

http://info1.ma.slu.se/db.html:

Databas för den nationella miljöövervakningens riksinventering av sjöar och vattendrag, Institutionen för miljöanalys, Sveriges Lantbruksuniversitet.

\section{Summary}

Northern Europe is a key area for the Blackthroated Diver Gavia arctica. 5500-7000 pairs breed in Sweden, and together with populations of a similar size in Finland and Norway, more than 95\% of the European population (outside Russia) breed in the Nordic countries. The species has increased in numbers in Sweden and Finland during the last decades, while it has decreased in Norway (BirdLife International 2004, Ottvall et al. 2008).

The aim of the present study is to relate the breeding success of the Black-throated Diver in 122 fresh-water lakes in Sweden to water chemistry and abundance of fish in the breeding lakes, and to compare these factors with fishing lakes used by Red-throated Diver Gavia stellata, using data from a previous study of 34 lakes (Eriksson 2006b). The Black-throated Divers feed their chicks mainly with fish (but also aquatic insects during the first weeks after hatching) caught in the breeding lake. In contrast, the Red-throated Diver breeds in small lakes and pools (mostly $<1$ ha), often devoid of fish, and the chicks are fed with fish brought by the parent birds from neighbouring larger lakes up to a distance of 9-10 km. 
The water chemistry is of importance for assessing the level of risks related to exposure to methylmercury, and in a longer-term perspective, the potential impact of climate change.

\section{Materials and methods}

The study lakes were selected from a total of 1800 lakes where the presence of at least one stationary (territory-holding) pair during at least one year during the period 1994-2008 had been confirmed, based on data from voluntary surveys (Projekt LOM, Eriksson 2006a). The criteria for selection were that data on the breeding success should be available for at least five years over the study period, in combination with access to information about water chemistry and/or occurrence of fish. These criteria were met for 122 lakes (primary data in Appendix A), which were assessed to contain 184 breeding pairs $(3 \%$ of the Swedish population). The results are assumed to be representative for the southern and central parts of Sweden, but with some reservation for the northern parts.

For each lake, the production of young was estimated by calculating the mean number of large chicks per stationary pair and year, according to published methods (e.g. Eriksson \& Hake 2000, Hake et al. 2005). The survival of chicks until fledged was assessed by calculating the mean percentage of broods with 2-3 large chicks per year. As the chick survival is largely related to the parent birds' capacity to catch fish for the young (e.g. Jackson 2003, 2005), this measure is an indication of the foraging conditions in the different lakes (primary data in Appendix A).

Water chemistry and light penetration information was primarily collected from national monitoring programmes, including large-scale surveys of lakes that are carried out with 5-years intervals (http://info1.ma.slu.se/db.html, Wilander et al. 2003 for methods etc). The parameters considered were:

- $p H$, as an indication of acidity. Many of the lakes were affected by acid precipitation during the $20^{\text {th }}$ century, with declines in fish stocks and increased water transparency being important effects on the foraging success by divers (e.g. Eriksson 1991, 1994, Brodin 1995). Several lakes have been limed regularly since the 1980 's, in order to counteract the negative impacts, although ecological changes may remain for a long time even if $\mathrm{pH}$ conditions have recovered (e.g. Appelberg 1995, Henrikson \& Brodin 1995).
- Alkalinity, as a measure of the capacity to buffer the impact of acid precipitation.

- Total phosphorus, as a measure of the nutrient status of the lake.

- Absorbance, as a measure of the light penetration.

- Secchi disc transparency, i.e. an alternative measure of light penetration and mostly done in connection to gill-net fishing. As the divers are visual predators, light conditions have been found to be of importance for the selection of lakes (Eriksson 1985, Eriksson \& Sundberg 1991, Kauppinen 1993).

The assessments of water chemistry followed the guidelines developed by the Swedish Environmental Protection Agency (Naturvårdsverket 1999); on the basis of mean values from at least two measurements during the period 1995-2007 (one measurement was accepted for Secchi dish transparency). Data was available for 74 lakes (58 lakes for total phosphorus, 54 lakes for Secchi disc transparency; primary data in Appendix B and D).

Fish stock information was collected from the database provided by the Swedish Board of Fisheries (NORS, www.fiskeriverket.se, search under "statistik och databaser"). For information about fish species, data from gill-net fishing with bottom nets during 1979-2008 was used (80 lakes, primary data in Appendix C). The abundance of fish was estimated on the basis of results from gill-net fishing during the period 1994-2008 (i.e. the same period as covered by "Projekt LOM"; 54 lakes, primary data in Appendix D). The mean number of fish per catch effort was used as an indirect measure of the density of fish, as recommended by the Swedish Board of Fisheries (Kinnerbäck 2001, no corrections were made with reference to potential net selectivity). For the analyses of any relationships between abundance of fish and the breeding result, the fish data was split up with reference to catches of Perch Perca fluvialitis, cyprinid fish, salmonid fish, Ruffe Gymnocephalus cernua, Pike Esox lucius and "other fish" (Table 2 and Appendix $\mathrm{C}$ for details).

Relationships between breeding performance and abundance of fish were investigated using multiple regression analyses. For an analysis including data both of water chemistry and fish abundance, information from 18 lakes was available. In addition, separate analyses were carried out for the production of young and the percentage of broods with 2-3 large chicks in relation to abundance of fish (51 and 12 lakes, respectively) and water chemistry (56 and 21 lakes, respectively). For fish, 
parallel analyses were done for the total catch and for small-sized fish $(<22 \mathrm{~cm})$, as the chicks have difficulty handling larger fish prey (e.g. Jackson 2003, 2005).

For the regression analyses, the function "lm" in R 2.8.1. (The foundation for statistical computing, 2008) was used. A step-wise algorithm (Hastie \& Pregiborn 1992, Faraway 2006, p. 21) was applied in order to reduce the number of variables and thereby improving the fit of the model. This procedure is based on the AIC (Akaike Information Criterion, Burnham \& Anderson 2002). This procedure optimizes the model both according to the degree of explained variation in the data set, $\mathrm{R}^{2}$, and the level of statistical significance. Pair-wise correlations were carried out in order to test the degree of co-variation between variables. Generally, alkalinity was strongly correlated with $\mathrm{pH}$ and thus excluded from all analyses.

A comparison of the breeding lakes of Blackthroated Diver and the fishing lakes of Red-throated Diver comprised 20 lakes with information about water chemistry and 18 lakes with information about fish stocks (Eriksson 2006b). Five lakes, included in the Red-throated Diver study as well as in the present study of the Black-throated Diver were excluded from the statistical analyses. The Mann-Whitney U test was used for the comparisons between the two kinds of lakes.

\section{Results}

Most of the breeding lakes of the Black-throated Diver were nutrient-poor. Low levels of phosphorus $(<0.013 \mathrm{mg} / \mathrm{l})$ were recorded in about one third of them, but the range was large and $7 \%$ of the lakes were classified as rich in nutrients $(>0.025 \mathrm{mg} / \mathrm{l})$. Nutrient status was similar in the fishing lakes of Red-throated Diver, with a mean level of 0.010 $\mathrm{mg} / \mathrm{l}$ in both kinds of lakes (Table 1, primary data in Appendix B). Around 40 of the lakes were moderately acidic ( $\mathrm{pH} 6.2-6.8)$, and $6 \%$ of them were acidic $(\mathrm{pH}<6.2)$. Alkalinity was satisfactory in most lakes, but low $(<0.10 \mathrm{meq} / \mathrm{l})$ in $12 \%$ of them. Both $\mathrm{pH}$ and alkalinity were lower in the fishing lakes of the Red-throated Diver, compared to the breeding lakes of the Black-throated Diver, with a mean $\mathrm{pH}$ of 6.4 and 6.8 , respectively, and alkalinity of 0.11 and 0.23 , respectively (Table 1 , after exclusion of the five lakes included in both studies). Approximately $70 \%$ of the Black-throated Diver lakes had moderately coloured water, as evaluated by absorbance values, and $4 \%$ of them were so strongly coloured that a brownish tint should be detectable by a human eye $\left(>0,2 \mathrm{f}_{250 / 5}\right)$. Transparency was high $(>5.0 \mathrm{~m})$ in $18 \%$ of the lakes. The fishing lakes of Red-throated Diver had on average less clear water than the lakes of Black-throated Diver; the absorbance was 0,14 and $0,11 \mathrm{f}_{250 / 5}$, respectively (Table 1 , primary data in Appendices B and D).

The species composition was typical for nutrient-poor lakes. In total, 26 species of fish were recorded from the 80 lakes investigated for this purpose (Table 2, primary data in Appendix C) with Perch, Roach Rutilus rutilus and Pike in at least $90 \%$ of them. Salmonid fish occurred in almost half of the lakes, with Whitefish Coregonus spp., Vendace Coregonus albula and Smelt Osmerus eperlanus being the most wide-spread species. Eel Anguilla anguilla is presumably found in almost all the investigated lakes, but it is rarely caught with the standardized methods used for gill-net fishing. The average number of species per lake was 6.0 but with a wide range, with some lakes having only 1-2 species and others having more than ten species (Figure 1). The mean number of fish species did not differ significantly between the Blackthroated Diver lakes and the fishing lakes used by Red-throated Diver, but salmonid fish occurred much more frequently in the Red-throated Diver lakes; 13 (93\%) of 14 of the fishing lakes used by Red-throated Diver compared to 35 (47\%) of 75 Black-throated Diver lakes (Figure 1; $\chi^{2}=8.36$, $\mathrm{df}=1, \mathrm{P}<0.01$, after exclusion of five lakes included in this investigation as well in the study of Redthroated Diver's fishing lakes).

Water chemistry and abundance of fish explained a substantial part of the variation in breeding success between the lakes (18 lakes; adjusted $\mathrm{R}^{2}=$ $50 \%$ and $49 \%$, respectively, for the total catch and small-sized fish, $\mathrm{P}=0.027$ in both cases; Table 3). There was a positive relationship for abundance of Perch and negative relationships for both total phosphorus and Secchi disc transparency (Figure $2)$. The regression analyses including only data on water chemistry (56 lakes) or only fish data (51 lakes) were not significant or could only explain a much smaller amount of the variation between lakes. The percentage of broods with 2-3 large chicks was highest in lakes with low absorbance, i.e. lakes with clear water (Figure $3, \mathrm{R}^{2}=26 \%, \mathrm{P}$ $=0.018 ; 21$ lakes, primary data from Appendices A and $\mathrm{B})$. There were no indications that the percentage of broods with 2-3 large chicks was related to the abundance of fish or water transparency (adjusted $\mathrm{R}^{2}=9 \%$, regression coefficient for Secchi disc transparency $=0.174 \pm$ S.E. $6.2, \mathrm{P}=0.17 ; 12$ lakes, primary data from Appendices A and D). 


\section{Discussion}

The breeding lakes of Black-throated Diver are generally nutrient-poor, mostly with fairly clear water. Around one tenth of them have a low buffering capacity. The species composition of the fish communities is typical for nutrient-poor lakes, although the number of fish species is highly variable; from only a few up to more than ten. The abundance of Perch is important for the breeding success, while light penetration affects the likelihood of the parent birds to find fish prey for the chicks and thereby to the survival of the young.

The negative relationship between breeding success and nutrient status (as indicated by total phosphorus) is in accordance with previous studies regarding the occurrence of Black-throated Diver in various lakes (e.g. Nilsson \& Nilsson 1978, Kauppinen 1993). However, the indication of a negative relationship between Secchi disc transparency was unexpected, considering previous results showing a preference for lakes with high transparency. Although light penetration affects the survival of chicks, this factor does not seem to influence the overall production of young significantly, presumably because most of the breeding failures are related to the incubation period (e.g. Hake et al. 2005).

The abundance of Pike did not affect the variation between lakes in breeding success; i.e. any predation pressure by Pike on diver chicks (Lehtonen 1970, Jackson 2003) was not to the extent that it affected the production or survival of young.

Although many of the fishing lakes of Redthroated Diver are also used by Black-throated Diver for breeding and foraging, there are overall differences in water chemistry and the species composition of the fish communities. Everywhere, the Red-throated Diver is bound to a narrower and more "exclusive" spectrum of lakes than the Blackthroated Diver. Generally, the fishing lakes used by Red-throated Diver have lower $\mathrm{pH}$ and alkalinity, and less clear water (Table 1). The preference of Red-throated Diver for lakes with salmonid fish was indicated in studies dating from the early 20th century (Rosenius 1942), later in various local and regional surveys (e.g. Andersson 1988, Borgström 1995), and further verified in this study (Figure 1). The survival of Red-throated Diver chicks is related to the abundance of salmonid and cyprinid fish in the fishing lakes used by the parent birds (Eriksson 2006b), while light penetration is more important for the Black-throated Diver parents in their search for fish prey for the chicks, and thus indirectly for their survival.
Although foraging and feeding of the chicks with prey caught in the breeding lake is the dominant behaviour by the Black-throated Diver, there is some flexibility with reference to foraging in other water-bodies than the breeding lake. Following the large-scale exploitation of most large rivers in Northern and Central Sweden for hydro-electric power production during the 20th century, many lakes in the catchment areas are now used as water reservoirs with water-level fluctuations of unnaturally high amplitude. In the River Skellefteälven, abundant stocks of small-sized whitefish have been established in some of the reservoirs and become an important food resource for both species of divers. The amplitude of water-level regulation is often too high to make successful breeding possible, but the Black-throated Diver has colonised surrounding smaller lakes for breeding while fish prey is still collected from the reservoirs (Bildström 2006). Reports from Norway also confirm that there are Black-throated Divers that have colonised small lakes $\left(<0.10 \mathrm{~km}^{2}\right)$ because of a lack of nesting sites at larger, mostly regulated, lakes from where the fish prey is still collected (Dunker \& Elgmork 1973).

In Southwest Sweden, a surprisingly high breeding success has been reported for Black-throated Diver pairs from lakes affected by acid precipitation and with substantially reduced fish stocks. The birds may have been able to compensate for the low abundance of fish by increased light penetration which makes it easier to find fish prey, and they may also have increased the proportion of aquatic insects in the diet (Eriksson 1986, 1991, 1994). Also, collecting fish from adjacent lakes up to a distance of at least 3-4 km has been recorded (Ahlgren 1996).

Scotland harbours a population of about 200 breeding pairs, concentrated in the north-western parts of the country. In many cases, the foraging pattern differs from that found in Sweden. In a study including 90 lakes (Jackson 2005), the Black-throated Diver bred almost entirely at lakes with a high abundance of small-sized salmonids, primarily Trout Salmo trutta, and most pairs breeding at lakes without salmonid fish collected fish prey for chicks from adjacent lakes. Also the fishes Minnow Phoxinus phoxinus and Three-spined Sticklebacks Gasterosteus aculeatus were abundant in the breeding lakes, and they constituted an additional important part in the chicks' diet. The breeding success was higher in lakes where the chicks were fed primarily on fish, compared to lakes were they were also fed on aquatic insects 
(Jackson 2003, 2005). The most common kind of breeding lakes used by the Black-throated Diver in Sweden, i.e. lakes where Perch, Roach and Pike are abundant and where chicks are regularly fed on aquatic insects during the first weeks after hatching (Lehtonen 1970, Sjölander 1978), are less common in Scotland and were considered to be suboptimal habitats.

Several lakes used by the two species of diver have a naturally low alkalinity, and many of them were affected by acid precipitation during the 20th century with a decline in fish stocks as the main consequence (Eriksson 1991, 1994). Lime treatment has been widely applied in order to restore the water quality and fish stocks. A successive phasing-out of the lime-treatment scheme has been initiated during recent years, however, continuous treatment for some decades will remain necessary in several lakes if the overall positive results with reference to ecological recovery of acidified lakes is to be safeguarded in the long-term (e.g. Henrikson \& Brodin 1995, Warfwinge \& Bertills 2000). With reference to the management of waterbird populations, priority should be focussed primarily on the fishing lakes of the Red-throated Diver, but also the breeding lakes of the Black-throated Diver should be considered for continued lime treatment when at risk of re-acidification (Eriksson 2006b).

Divers are top predators at the end of an aquatic food-chain and they are thus susceptible to bioaccumulation of toxic substances. For fish-eating birds, heavy metals and primarily methylmercury have been recognised as potentially dangerous (e.g. Scheuhammer 1991). There are, however, few studies from the Nordic countries that reflect this problem. In the 1970s the exposure to birds of various toxic elements was studied at Lake Päijänne, the second largest lake in Finland, and from approximately ten bird species, contents of mercury in samples from Black-throated Diver and Common Merganser Mergus merganser were much higher than from other species (Särkkä et al. 1978). Analyses of diver eggs collected in Sweden during the 1980s and 1990s indicated higher mean levels of mercury in eggs of Red-throated Diver than in Black-throated Diver (with very high contents and possible risk for reproductive impairment in some cases). The contents in Black-throated Diver eggs collected at lakes affected by acidification were generally higher compared with eggs from other lakes (Eriksson \& Lindberg 2005).

More recently, leakage of air-borne mercury (related to emissions from fossil fuels) from terrestrial to aquatic habitats has attracted increased attention (e.g. Skyllberg 2003, Evers et al. 2007). In Sweden there are recent reports of an increase in the amount of mercury in freshwater fish, breaking a continuously declining trend since the 1960s (Åkerblom \& Johansson 2008). The risk of exposure to methylmercury is closely related to the water chemistry. Recent studies in North-eastern USA suggest that the risk for top predators is substantial in nutrientpoor lakes; with proposed indicators of total phosphorus $<0.03 \mathrm{mg} / \mathrm{l}$ in combination with $\mathrm{pH}<6.0$, alkalinity $<0.10 \mathrm{meq} / 1$ or dissolved organic carbon (DOC) $>4 \mathrm{mg} / \mathrm{l}$ for lakes being susceptible (Driscoll et al. 2007). In the present study, total phosphorus was at or below the above indicated limit of $0.03 \mathrm{mg} / \mathrm{l}$ in the majority of the breeding lakes of Black-throated Diver (56 of 58 lakes with phosphorus data, Appendix A) and all fishing lakes of Red-throated Diver investigated (Table 1). Based on data on $\mathrm{pH}$ and alkalinity, and by assuming that the results can be generalised for the whole of Sweden, we assumed that almost $10 \%$ of the breeding lakes of Black-throated Diver and more than 30\% of the fishing lakes used by Red-throated Diver are at risk for high exposure to methylmercury related to leakage from forest and wetland habitats in the catchment areas.

Both the Black-throated and the Red-throated Diver are forecasted to have disappeared from the southern and central parts of Sweden and large parts of Finland by 2090 because of climate change (Huntley et al. 2009). With reference to the breeding and foraging lakes, it is very likely that factors important for divers, such as light penetration and abundance of fish will be affected, but it seems to be extremely difficult to make more precise predictions for the kind of nutrient-poor lakes where the birds are primarily found (e.g. Nordiska Ministerrådet 2005). Shorter periods of ice-cover in winter and higher water temperature may lead to consequences of relevance for the divers. A prolonged vegetation period may be beneficial for the macrophyte vegetation, with only a moderate change in light penetration and nutrient status as consequences, but alternatively an increased algae production may result in more nutrient-rich conditions, increased contents of dissolved organic material and hence reduced light penetration. This might have impact on the species composition of the fish communities with decreased abundance of Perch and Pike while various species of cyprinid fish may benefit. In lakes following this scenario, foraging conditions for both species of divers may be substantially affected. 
Appendix A.

Undersökta häckningssjöar för storlom.

Breeding lakes for Black-throated Diver, included in the present study.

\begin{tabular}{|c|c|c|c|c|c|c|c|c|c|c|c|c|c|}
\hline \multirow[t]{2}{*}{$\begin{array}{l}\text { Sjö } \\
\text { Lake }\end{array}$} & \multirow[t]{2}{*}{$\begin{array}{l}\text { Läns- } \\
\text { kod }^{c} \\
\text { County } \\
\text { code }\end{array}$} & \multicolumn{2}{|c|}{$\begin{array}{l}\text { Koordinater } \\
\text { Rikets nät } \\
\text { Coordinates } \\
\text { national grid }\end{array}$} & \multirow{2}{*}{$\begin{array}{c}\text { Vatten- } \\
\text { kemi } \\
\text { Water } \\
\text { chem- } \\
\text { istry } \\
\text { App. } \\
\text { B }\end{array}$} & \multirow{2}{*}{$\begin{array}{c}\text { Fisk- } \\
\text { arter } \\
\text { Fish } \\
\text { species } \\
\text { App. } \\
\text { C }\end{array}$} & \multirow{2}{*}{$\begin{array}{c}\text { Prov- } \\
\text { fiske } \\
\text { Gill } \\
\text { net } \\
\text { fishing } \\
\text { App. } \\
\text { D }\end{array}$} & \multicolumn{2}{|c|}{$\begin{array}{c}\text { Antal stora } \\
\text { ungar per par } \\
\text { och år } \\
\text { Number of large } \\
\text { chicks per pair } \\
\text { and year }\end{array}$} & \multicolumn{2}{|c|}{$\begin{array}{l}\text { \% kullar med } \\
2-3 \text { stora ungar } \\
\text { per år } \\
\% \text { broods with } \\
2-3 \text { large } \\
\text { chicks per year }\end{array}$} & \multirow[t]{2}{*}{\begin{tabular}{|c|}
$\begin{array}{c}\text { Antal } \\
\text { par }^{\mathrm{a}}\end{array}$ \\
No. \\
of \\
pairs $^{a}$
\end{tabular}} & \multirow[t]{2}{*}{$\begin{array}{c}\begin{array}{c}\text { Areal- } \\
\text { kod }^{\mathrm{b}}\end{array} \\
\text { Surface } \\
\text { area } \\
\text { code }^{b}\end{array}$} & \multirow[t]{2}{*}{$\begin{array}{c}\begin{array}{c}\text { Areal } \\
\mathrm{km}^{2}\end{array} \\
\text { Surface } \\
\text { area } \\
\mathrm{km}^{2}\end{array}$} \\
\hline & & $\mathrm{X}$ & $\mathrm{Y}$ & & & & $\begin{array}{l}\text { Medel } \\
\text { Mean }\end{array}$ & $\begin{array}{c}\text { Ar } \\
\text { Years }\end{array}$ & $\begin{array}{l}\text { Medel } \\
\text { Mean }\end{array}$ & $\begin{array}{c}\AA \mathrm{Ar} \\
\text { Years }\end{array}$ & & & \\
\hline Store Damm & M & 622349 & 135317 & & $\mathrm{X}$ & $\mathrm{X}$ & 0,50 & 6 & - & 3 & 1 & $\mathrm{C}$ & 1,31 \\
\hline Raslången & $\mathrm{K}, \mathrm{M}$ & 623815 & 141620 & $\mathrm{X}$ & $\mathrm{X}$ & & 0,80 & 5 & - & 3 & 1 & $\mathrm{C}$ & 4,54 \\
\hline Lärkesholmssjön & $\mathrm{M}$ & 624178 & 134911 & & $\mathrm{X}$ & $\mathrm{X}$ & 0,00 & 6 & - & 0 & 1 & $\mathrm{D}$ & 0,76 \\
\hline Immeln & $\mathrm{M}$ & 624180 & 141251 & $\mathrm{X}$ & $\mathrm{X}$ & $\mathrm{X}$ & 0,00 & 5 & - & 0 & 1 & B & 24,28 \\
\hline Rössjön & M & 624598 & 133125 & $\mathrm{X}$ & $\mathrm{X}$ & $\mathrm{X}$ & 0,20 & 10 & - & 2 & 1 & $\mathrm{C}$ & 3,71 \\
\hline Värsjö & M & 624606 & 135677 & $\mathrm{X}$ & $\mathrm{X}$ & $\mathrm{X}$ & 0,84 & 15 & $33 \%$ & 15 & 3 & $\mathrm{C}$ & 3,00 \\
\hline Fedingesjön & $\mathrm{M}$ & 625371 & 135680 & $\mathrm{X}$ & & & 0,33 & 6 & - & 2 & 1 & $\mathrm{D}$ & 0,94 \\
\hline Skäravattnet & G & 626277 & 142200 & & $\mathrm{X}$ & $\mathrm{X}$ & 0,00 & 5 & - & 0 & 1 & $\mathrm{D}$ & 0,50 \\
\hline Getsjön & G & 626407 & 142157 & & $\mathrm{X}$ & $\mathrm{X}$ & 0,17 & 6 & - & 2 & 1 & $\mathrm{D}$ & 0,70 \\
\hline Vinen & G & 627275 & 142183 & & $\mathrm{X}$ & $\mathrm{X}$ & 0,36 & 7 & - & 2 & 2 & $\mathrm{C}$ & 3,15 \\
\hline Övden & $\mathrm{G}$ & 627654 & 141929 & & $\mathrm{X}$ & $\mathrm{X}$ & 0,80 & 5 & - & 4 & 2 & $\mathrm{C}$ & 1,21 \\
\hline Skärsjön, Dagsås & $\mathrm{N}$ & 633344 & 130068 & & $\mathrm{X}$ & $\mathrm{X}$ & 0,00 & 6 & - & 0 & 2 & $\mathrm{C}$ & 2,80 \\
\hline Valasjön, Dagsås & $\mathrm{N}$ & 633503 & 130204 & $\mathrm{X}$ & $\mathrm{X}$ & $\mathrm{X}$ & - & 4 & $40 \%$ & 5 & 1 & $\mathrm{D}$ & 0,74 \\
\hline Hurven & $\mathrm{F}$ & 633911 & 134035 & $\mathrm{X}$ & $\mathrm{X}$ & $\mathrm{X}$ & 0,44 & 9 & - & 4 & 1 & $\mathrm{C}$ & 1,69 \\
\hline Svarten & $\mathrm{N}$ & 634039 & 130685 & & $\mathrm{X}$ & $\mathrm{X}$ & 0,00 & 6 & - & 0 & 1 & $\mathrm{C}$ & 1,30 \\
\hline Stora Neten & $\mathrm{N}$ & 634378 & 130353 & $\mathrm{X}$ & $\mathrm{X}$ & $\mathrm{X}$ & 0,11 & 9 & - & 1 & 1 & $\mathrm{C}$ & 3,17 \\
\hline Norra Svansjön & $\mathrm{O}$ & 634451 & 133674 & $\mathrm{X}$ & & & 0,21 & 6 & - & 4 & 2 & $\mathrm{D}$ & 0,86 \\
\hline Furesjön, Nösslinge & $\mathrm{N}$ & 634529 & 130569 & & $\mathrm{X}$ & $\mathrm{X}$ & 0,17 & 6 & - & 1 & 1 & $\mathrm{D}$ & 0,43 \\
\hline Barken & $\mathrm{N}$ & 634751 & 130909 & & $\mathrm{X}$ & $\mathrm{X}$ & 0,20 & 5 & - & 1 & 1 & $\mathrm{C}$ & 1,20 \\
\hline Sävsjön, Arnåsholm & $\mathrm{F}$ & 635030 & 135088 & & $\mathrm{X}$ & $\mathrm{X}$ & 0,25 & 12 & - & 3 & 1 & $\mathrm{C}$ & 1,50 \\
\hline Fegen & $\mathrm{O}, \mathrm{N}, \mathrm{F}$ & 635040 & 133900 & $\mathrm{X}$ & $\mathrm{X}$ & $\mathrm{X}$ & 0,33 & 13 & $10 \%$ & 9 & 15 & $\mathrm{~B}$ & 23,70 \\
\hline Skärsjön, Karl-Gustav & $\mathrm{N}$ & 635198 & 130537 & & $\mathrm{X}$ & $\mathrm{X}$ & 0,50 & 8 & - & 3 & 1 & $\mathrm{D}$ & 0,41 \\
\hline Grysjön & $\mathrm{O}$ & 636289 & 134951 & $\mathrm{X}$ & $\mathrm{X}$ & $\mathrm{X}$ & 0,18 & 11 & - & 2 & 1 & $\mathrm{D}$ & 0,59 \\
\hline Yttre Älvsjön & $\mathrm{O}$ & 636452 & 134376 & $\mathrm{X}$ & & & 0,30 & 10 & - & 2 & 1 & $\mathrm{D}$ & 0,31 \\
\hline Älgsjön, Öxabäck & $\mathrm{O}$ & 636479 & 132039 & $\mathrm{X}$ & & & 0,70 & 10 & $40 \%$ & 5 & 1 & $\mathrm{D}$ & 0,36 \\
\hline Stora Horredsjön & $\mathrm{O}, \mathrm{N}$ & 636512 & 129668 & $\mathrm{X}$ & $\mathrm{X}$ & $\mathrm{X}$ & 0,20 & 10 & - & 4 & 1 & $\mathrm{C}$ & 5,93 \\
\hline Helsjön & $\mathrm{N}, \mathrm{O}$ & 636522 & 129475 & & $\mathrm{X}$ & $\mathrm{X}$ & 0,40 & 5 & - & 2 & 1 & $\mathrm{D}$ & 0,17 \\
\hline Öxasjön & $\mathrm{O}$ & 636696 & 131979 & $\mathrm{X}$ & & & 0,83 & 12 & $44 \%$ & 9 & 1 & $\mathrm{D}$ & 0,30 \\
\hline Algutstorpasjön & F & 636801 & 136926 & & $\mathrm{X}$ & $\mathrm{X}$ & 0,50 & 6 & $0 \%$ & 5 & 2 & $\mathrm{C}$ & 1,04 \\
\hline Lövsjö & $\mathrm{N}$ & 636911 & 129516 & $\mathrm{X}$ & $\mathrm{X}$ & & 0,11 & 9 & - & 1 & 1 & $\mathrm{D}$ & 0,57 \\
\hline Fagerhultasjön & $\mathrm{F}$ & 637469 & 147319 & & $\mathrm{X}$ & $\mathrm{X}$ & 0,33 & 12 & - & 4 & 1 & $\mathrm{C}$ & 1,69 \\
\hline Stora Bellen & $\mathrm{F}$ & 637794 & 147338 & & $\mathrm{X}$ & $\mathrm{X}$ & 0,50 & 6 & $20 \%$ & 5 & 2 & $\mathrm{C}$ & 6,92 \\
\hline Lagmanshagasjön & $\mathrm{O}$ & 638014 & 136892 & & $\mathrm{X}$ & $\mathrm{X}$ & 0,50 & 6 & - & 2 & 1 & $\mathrm{C}$ & 3,08 \\
\hline Mycklaflon & $\mathrm{F}$ & 638146 & 146910 & $\mathrm{X}$ & $\mathrm{X}$ & $\mathrm{X}$ & 0,63 & 9 & $80 \%$ & 5 & 2 & B & 11,55 \\
\hline Gissen & $\mathrm{H}$ & 638315 & 150078 & $\mathrm{X}$ & $\mathrm{X}$ & $\mathrm{X}$ & 0,14 & 7 & - & 1 & 1 & $\mathrm{C}$ & 1,67 \\
\hline Skedesjön & $\mathrm{F}$ & 638513 & 146360 & & $\mathrm{X}$ & $\mathrm{X}$ & 0,64 & 6 & - & 3 & 2 & $\mathrm{C}$ & 3,48 \\
\hline Hjälten & $\mathrm{F}$ & 638963 & 147247 & & $\mathrm{X}$ & & 1,42 & 6 & $50 \%$ & 6 & 1 & $\mathrm{D}$ & 0,50 \\
\hline Södra Vixen & F & 639017 & 144472 & $\mathrm{X}$ & $\mathrm{X}$ & $\mathrm{X}$ & 0,76 & 12 & $40 \%$ & 10 & 2 & $\mathrm{C}$ & 5,10 \\
\hline Frisjön & $\mathrm{F}$ & 639134 & 132882 & $\mathrm{X}$ & & & 0,30 & 15 & $28 \%$ & 9 & 3 & $\mathrm{C}$ & 6,85 \\
\hline Västra Ingsjön & $\mathrm{O}$ & 639243 & 128795 & $\mathrm{X}$ & & & 0,83 & 6 & - & 4 & 1 & $\mathrm{C}$ & 2,30 \\
\hline Norra Vixen & F & 639254 & 144481 & $\mathrm{X}$ & & & 0,35 & 14 & $33 \%$ & 6 & 3 & $\mathrm{C}$ & 1,71 \\
\hline Försjön & $\mathrm{F}$ & 639260 & 145910 & & $\mathrm{X}$ & $\mathrm{X}$ & 0,31 & 15 & $18 \%$ & 10 & 4 & $\mathrm{C}$ & 2,62 \\
\hline Lövsjön & $\mathrm{F}$ & 639266 & 146764 & & $\mathrm{X}$ & & 0,60 & 5 & - & 3 & 1 & $\mathrm{D}$ & 0,39 \\
\hline Nässjasjön & F & 639313 & 147403 & $\mathrm{X}$ & $\mathrm{X}$ & & 0,40 & 5 & - & 1 & 1 & $\mathrm{D}$ & 0,32 \\
\hline Storsjön, Viskafors & F & 639330 & 132199 & $\mathrm{X}$ & & & 0,36 & 14 & - & 4 & 1 & $\mathrm{C}$ & 1,54 \\
\hline Hunsnäsen & F & 539412 & 145078 & $\mathrm{X}$ & & & 0,60 & 15 & $13 \%$ & 8 & 1 & $\mathrm{D}$ & 0,76 \\
\hline Västre Sjön & $\mathrm{F}$ & 639489 & 146510 & & $\mathrm{X}$ & & 0,40 & 5 & - & 1 & 1 & $\mathrm{D}$ & 0,39 \\
\hline
\end{tabular}




\begin{tabular}{|c|c|c|c|c|c|c|c|c|c|c|c|c|c|}
\hline \multirow[t]{2}{*}{\begin{tabular}{|l|} 
Sjö \\
Lake
\end{tabular}} & \multirow[t]{2}{*}{\begin{tabular}{|c|}
$\begin{array}{c}\text { Läns- } \\
\text { kod }^{c}\end{array}$ \\
County \\
code
\end{tabular}} & \multicolumn{2}{|c|}{$\begin{array}{l}\text { Koordinater } \\
\text { Rikets nät } \\
\text { Coordinates } \\
\text { national grid }\end{array}$} & \multirow{2}{*}{$\begin{array}{c}\begin{array}{c}\text { Vatten- } \\
\text { kemi }\end{array} \\
\text { Water } \\
\text { chem- } \\
\text { istry } \\
\text { App. } \\
\mathrm{B} \\
\end{array}$} & \multirow{2}{*}{$\begin{array}{c}\text { Fisk- } \\
\text { arter } \\
\text { Fish } \\
\text { species } \\
\text { App. } \\
\text { C }\end{array}$} & \multirow{2}{*}{\begin{tabular}{|c}
$\begin{array}{c}\text { Prov- } \\
\text { fiske }\end{array}$ \\
Gill \\
net \\
fishing \\
App. \\
D
\end{tabular}} & \multicolumn{2}{|c|}{$\begin{array}{c}\text { Antal stora } \\
\text { ungar per par } \\
\text { och år } \\
\text { Number of large } \\
\text { chicks per pair } \\
\text { and year }\end{array}$} & \multicolumn{2}{|c|}{\begin{tabular}{|c|} 
\% kullar med \\
$2-3$ stora ungar \\
per år \\
\% broods with \\
2-3 large \\
chicks per year
\end{tabular}} & \multirow[t]{2}{*}{\begin{tabular}{|}
$\begin{array}{c}\text { Antal } \\
\text { par }^{\mathrm{a}}\end{array}$ \\
No. \\
of \\
pairs $^{a}$
\end{tabular}} & \multirow[t]{2}{*}{$\begin{array}{c}\begin{array}{c}\text { Areal- } \\
\text { kod }^{\mathrm{b}}\end{array} \\
\text { Surface } \\
\text { area }^{\text {code }^{b}}\end{array}$} & \multirow[t]{2}{*}{\begin{tabular}{|c}
$\begin{array}{c}\text { Areal } \\
\mathrm{km}^{2}\end{array}$ \\
Surface \\
area \\
$\mathrm{km}^{2}$
\end{tabular}} \\
\hline & & $\mathrm{X}$ & $\mathrm{Y}$ & & & & $\begin{array}{l}\text { Medel } \\
\text { Mean }\end{array}$ & $\begin{array}{c}\text { År } \\
\text { Years }\end{array}$ & $\begin{array}{l}\text { Medel } \\
\text { Mean }\end{array}$ & $\begin{array}{c}\text { År } \\
\text { Years }\end{array}$ & & & \\
\hline Finnsjön & $\mathrm{O}$ & 639565 & 128173 & $\mathrm{X}$ & & & 0,55 & 11 & - & 4 & 2 & $\mathrm{C}$ & 1,06 \\
\hline Yxsjön & $\mathrm{O}$ & 639716 & 128396 & $\mathrm{X}$ & & & 0,14 & 14 & - & 1 & 1 & $\mathrm{C}$ & 1,04 \\
\hline Trehörningen, Komosse & $\mathrm{O}$ & 639725 & 137271 & $\mathrm{X}$ & & & 0,00 & 6 & - & 1 & 1 & $\mathrm{C}$ & 1,61 \\
\hline Härstensbosjön & $\mathrm{F}$ & 639944 & 145257 & & $\mathrm{X}$ & & 0,00 & 5 & - & 0 & 1 & $\mathrm{D}$ & 0,83 \\
\hline Viaredssjön & $\mathrm{O}$ & 640086 & 131710 & $\mathrm{X}$ & $\mathrm{X}$ & & 0,43 & 14 & $0 \%$ & 6 & 1 & $\mathrm{C}$ & 3,79 \\
\hline Pickesjön & $\mathrm{O}$ & 640128 & 132565 & $\mathrm{X}$ & & & 0,79 & 14 & $33 \%$ & 9 & 1 & $\mathrm{D}$ & 0,28 \\
\hline Östra Nedsjön & $\mathrm{O}$ & 640458 & 130232 & $\mathrm{X}$ & $\mathrm{X}$ & & 0,44 & 9 & - & 4 & 1 & $\mathrm{C}$ & 7,40 \\
\hline Hornasjön & $\mathrm{O}$ & 640473 & 129112 & $\mathrm{X}$ & $\mathrm{X}$ & & 0,35 & 10 & - & 3 & 1 & $\mathrm{C}$ & 1,36 \\
\hline Sandsjön, Härryda & $\mathrm{O}$ & 640497 & 128906 & $\mathrm{X}$ & & & 0,40 & 5 & - & 2 & 1 & D & 0,89 \\
\hline Stora Sturven & $\mathrm{O}$ & 640619 & 129618 & $\mathrm{X}$ & $\mathrm{X}$ & $\mathrm{X}$ & 0,20 & 15 & - & 4 & 2 & $\mathrm{C}$ & 1,04 \\
\hline Stora Stamsjön & $\mathrm{O}$ & 640680 & 128957 & & $\mathrm{X}$ & $\mathrm{X}$ & 0,62 & 13 & $60 \%$ & 5 & 1 & $\mathrm{D}$ & 0,67 \\
\hline Tvärsjön & $\mathrm{O}$ & 640773 & 129726 & $\mathrm{X}$ & & & 0,07 & 14 & - & 1 & 1 & $\mathrm{D}$ & 0,89 \\
\hline Vibosjön & $\mathrm{O}$ & 640980 & 130033 & $\mathrm{X}$ & $\mathrm{X}$ & & 0,36 & 11 & - & 3 & 1 & $\mathrm{D}$ & 0,57 \\
\hline Uspen & $\mathrm{O}$ & 641068 & 129720 & $\mathrm{X}$ & & & 0,47 & 15 & $40 \%$ & 5 & 1 & $\mathrm{C}$ & 1,40 \\
\hline Västra Lägern & E,F & 641225 & 145772 & $\mathrm{X}$ & $\mathrm{X}$ & $\mathrm{X}$ & 0,40 & 5 & - & 2 & 1 & $\mathrm{~B}$ & 11,34 \\
\hline Sälsjön & $\mathrm{O}$ & 641649 & 131981 & $\mathrm{X}$ & & & 0,60 & 10 & $20 \%$ & 5 & 1 & D & 0,18 \\
\hline Brängen & $\mathrm{O}, \mathrm{F}$ & 641863 & 137912 & $\mathrm{X}$ & & & 0,17 & 15 & - & 3 & 1 & $\mathrm{C}$ & 2,60 \\
\hline Stora Tränningen & $\mathrm{O}$ & 642059 & 132162 & & $\mathrm{X}$ & $\mathrm{X}$ & 0,67 & 6 & - & 2 & 1 & $\mathrm{C}$ & 1,02 \\
\hline Stora Öjasjön, Hökensås & $\mathrm{O}$ & 643887 & 139802 & $\mathrm{X}$ & & & 1,20 & 5 & - & 3 & 1 & $\mathrm{D}$ & - \\
\hline Vristulven & $\mathrm{O}$ & 649519 & 137757 & & $\mathrm{X}$ & $\mathrm{X}$ & 0,22 & 13 & - & 4 & 2 & $\mathrm{C}$ & 4,54 \\
\hline $\begin{array}{l}\text { Stora Holmevatten, } \\
\text { Kynnefjäll }\end{array}$ & $\mathrm{O}$ & 651960 & 126392 & $\mathrm{X}$ & $\mathrm{X}$ & $\mathrm{X}$ & 0,64 & 14 & $11 \%$ & 9 & 1 & $\mathrm{C}$ & 1,00 \\
\hline Löv, Kynnefjäll & $\mathrm{O}$ & 652129 & 126593 & & $\mathrm{X}$ & $\mathrm{X}$ & 0,38 & 13 & - & 4 & 1 & $\mathrm{D}$ & 0,37 \\
\hline Sälesjön, Kynnefjäll & $\mathrm{O}$ & 652280 & 126317 & & $\mathrm{X}$ & $\mathrm{X}$ & 0,40 & 5 & - & 1 & 1 & $\mathrm{D}$ & 0,40 \\
\hline Skottbackatjärn & $\mathrm{O}$ & 653480 & 127241 & $\mathrm{X}$ & & & 0,70 & 10 & $57 \%$ & 7 & 1 & $\mathrm{D}$ & 0,18 \\
\hline Fjättersjön & $\mathrm{AB}$ & 653600 & 162119 & $\mathrm{X}$ & & & 0,75 & 6 & - & 4 & 1 & $\mathrm{D}$ & 0,49 \\
\hline Sottern & $\mathrm{T}$ & 654370 & 148479 & $\mathrm{X}$ & $\mathrm{X}$ & & 0,27 & 15 & $25 \%$ & 14 & 15 & B & 26,75 \\
\hline Stora Tresticklan & $\mathrm{O}$ & 655209 & 126937 & & $\mathrm{X}$ & & 0,15 & 13 & - & 2 & 1 & $\mathrm{C}$ & 1,08 \\
\hline Valsebotjärn & $\mathrm{O}$ & 655651 & 127926 & $\mathrm{X}$ & & & 0,54 & 13 & $50 \%$ & 6 & 1 & D & 0,29 \\
\hline Teen & $\mathrm{T}$ & 655681 & 143519 & $\mathrm{X}$ & & & 0,32 & 14 & $14 \%$ & 7 & 2 & $\mathrm{C}$ & 6,00 \\
\hline Stor-Björken & $\mathrm{T}$ & 655695 & 142624 & & $\mathrm{X}$ & $\mathrm{X}$ & 0,10 & 5 & - & 1 & 1 & $\mathrm{C}$ & 4,32 \\
\hline Acksjön & $\mathrm{D}$ & 655707 & 155934 & $\mathrm{X}$ & & & 0,43 & 14 & $20 \%$ & 5 & 1 & $\mathrm{D}$ & - \\
\hline Lilla Ulvattnet & $\mathrm{O}$ & 655830 & 127145 & $\mathrm{X}$ & & & 0,54 & 13 & $40 \%$ & 5 & 1 & $\mathrm{D}$ & 0,20 \\
\hline Gravdalssjön & $\mathrm{O}$ & 656749 & 127081 & $\mathrm{X}$ & & & 1,65 & 10 & $63 \%$ & 12 & 1 & $\mathrm{C}$ & 1,36 \\
\hline Stensjön, Tyresta NP & $\mathrm{AB}$ & 656419 & 164404 & & $\mathrm{X}$ & $\mathrm{X}$ & 0,29 & 7 & - & 1 & 1 & $\mathrm{D}$ & 0,42 \\
\hline Ältaren & $\mathrm{D}$ & 656521 & 155820 & & $\mathrm{X}$ & & 0,42 & 12 & - & 3 & 1 & $\mathrm{D}$ & 0,28 \\
\hline Årsjön & $\mathrm{AB}$ & 656612 & 164132 & & $\mathrm{X}$ & $\mathrm{X}$ & 0,40 & 5 & - & 1 & 1 & $\mathrm{D}$ & 0,21 \\
\hline Östra Magsjön & $\mathrm{D}$ & 656614 & 156319 & & $\mathrm{X}$ & & 0,54 & 9 & $0 \%$ & 6 & 1 & $\mathrm{C}$ & 1,53 \\
\hline Stora Grytsjön & $\mathrm{D}$ & 656828 & 154713 & & $\mathrm{X}$ & $\mathrm{X}$ & 0,17 & 6 & - & 2 & 1 & $\mathrm{D}$ & 0,31 \\
\hline Näshultasjön & $\mathrm{D}$ & 656853 & 152800 & $\mathrm{X}$ & & & 0,66 & 9 & $31 \%$ & 7 & 3 & B & 10,23 \\
\hline Albysjön & $\mathrm{AB}$ & 656984 & 164254 & & $\mathrm{X}$ & $\mathrm{X}$ & 0,83 & 6 & - & 4 & 1 & $\mathrm{D}$ & 0,70 \\
\hline Flaten & $\mathrm{AB}$ & 657143 & 163427 & & $\mathrm{X}$ & $\mathrm{X}$ & 0,40 & 5 & - & 2 & 1 & $\mathrm{D}$ & 0,64 \\
\hline Bornsjön & $\mathrm{AB}$ & 657245 & 160890 & $\mathrm{X}$ & $\mathrm{X}$ & $\mathrm{X}$ & 0,07 & 7 & - & 1 & 1 & $\mathrm{C}$ & 6,78 \\
\hline Kullaträsket & $\mathrm{AB}$ & 657424 & 165233 & $\mathrm{X}$ & & & 0,33 & 6 & - & 2 & 1 & $\mathrm{D}$ & 0,20 \\
\hline Aspviksträsket & $\mathrm{AB}$ & 658291 & 164891 & $\mathrm{X}$ & & & 0,33 & 6 & - & 1 & 1 & $E$ & - \\
\hline Stora Le & $\mathrm{O}, \mathrm{S}$ & 658500 & 127455 & $\mathrm{X}$ & $\mathrm{X}$ & & 0,52 & 14 & $20 \%$ & 9 & (3) & B & 86,19 \\
\hline Träsksjön & $\mathrm{AB}$ & 658943 & 163638 & $\mathrm{X}$ & $\mathrm{X}$ & $\mathrm{X}$ & 0,14 & 7 & - & 1 & 1 & $\mathrm{E}$ & 0,10 \\
\hline Säbysjön & $\mathrm{AB}$ & 659147 & 161733 & & $\mathrm{X}$ & & 0,35 & 10 & $20 \%$ & 5 & 2 & $\mathrm{D}$ & 0,77 \\
\hline Nedre Hurr & $\mathrm{S}$ & 660550 & 127332 & & $\mathrm{X}$ & $\mathrm{X}$ & - & 1 & $33 \%$ & 6 & 1 & $\mathrm{D}$ & 0,90 \\
\hline Tärnan & $\mathrm{AB}$ & 660688 & 164478 & $\mathrm{X}$ & $\mathrm{X}$ & $\mathrm{X}$ & 0,50 & 6 & - & 2 & 1 & $\mathrm{C}$ & 1,12 \\
\hline Malmsjön & $\mathrm{AB}$ & 661173 & 164515 & $\mathrm{X}$ & $\mathrm{X}$ & $\mathrm{X}$ & 0,50 & 6 & - & 2 & 1 & $\mathrm{D}$ & 0,27 \\
\hline Rinnen (Håltebyrinnen) & $\mathrm{S}$ & 661549 & 128928 & & $\mathrm{X}$ & & - & 1 & $80 \%$ & 5 & 1 & $\mathrm{C}$ & 1,24 \\
\hline
\end{tabular}




\begin{tabular}{|c|c|c|c|c|c|c|c|c|c|c|c|c|c|}
\hline \multirow[t]{2}{*}{$\begin{array}{l}\text { Sjö } \\
\text { Lake }\end{array}$} & \multirow[t]{2}{*}{$\begin{array}{l}\begin{array}{l}\text { Läns- } \\
\text { kod }^{c}\end{array} \\
\text { County } \\
\text { code }^{c}\end{array}$} & \multicolumn{2}{|c|}{$\begin{array}{l}\text { Koordinater } \\
\text { Rikets nät } \\
\text { Coordinates } \\
\text { national grid }\end{array}$} & \multirow{2}{*}{$\begin{array}{c}\text { Vatten- } \\
\text { kemi } \\
\text { Water } \\
\text { chem- } \\
\text { istry } \\
\text { App. } \\
\text { B }\end{array}$} & \multirow{2}{*}{ 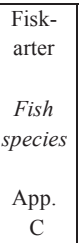 } & \multirow{2}{*}{$\begin{array}{c}\text { Prov- } \\
\text { fiske } \\
\\
\text { Gill } \\
\text { net } \\
\text { fishing } \\
\text { App. } \\
\text { D }\end{array}$} & \multicolumn{2}{|c|}{$\begin{array}{c}\text { Antal stora } \\
\text { ungar per par } \\
\text { och år } \\
\text { Number of large } \\
\text { chicks per pair } \\
\text { and year }\end{array}$} & \multicolumn{2}{|c|}{\begin{tabular}{|c} 
\% kullar med \\
$2-3$ stora ungar \\
per år \\
\% broods with \\
2-3 large \\
chicks per year
\end{tabular}} & \multirow[t]{2}{*}{\begin{tabular}{|c|}
$\begin{array}{c}\text { Antal } \\
\text { par }^{\mathrm{a}}\end{array}$ \\
\\
No. \\
of \\
pairs $^{a}$
\end{tabular}} & \multirow[t]{2}{*}{$\begin{array}{l}\begin{array}{c}\text { Areal- } \\
\text { kod }^{\mathrm{b}}\end{array} \\
\text { Surface } \\
\text { area } \\
\text { code }^{b}\end{array}$} & \multirow[t]{2}{*}{\begin{tabular}{|c}
$\begin{array}{c}\text { Areal } \\
\mathrm{km}^{2}\end{array}$ \\
Surface \\
area \\
$\mathrm{km}^{2}$
\end{tabular}} \\
\hline & & $\mathrm{X}$ & $\mathrm{Y}$ & & & & $\begin{array}{c}\text { Medel } \\
\text { Mean }\end{array}$ & $\begin{array}{c}\text { År } \\
\text { Years }\end{array}$ & $\begin{array}{l}\text { Medel } \\
\text { Mean }\end{array}$ & $\begin{array}{c}\AA r \\
\text { Years }\end{array}$ & & & \\
\hline Saxen & $\mathrm{S}$ & \begin{tabular}{|l|}
662551 \\
\end{tabular} & 142470 & $\mathrm{X}$ & & & - & 4 & $33 \%$ & 6 & 1 & $\mathrm{C}$ & 6,84 \\
\hline Ösmaren & $\mathrm{AB}$ & 664222 & 166844 & $\mathrm{X}$ & & & 0,00 & 6 & - & 0 & 1 & $\mathrm{C}$ & 1,43 \\
\hline Mellan-Lersjön & S & 664310 & 129762 & & $\mathrm{X}$ & & - & 1 & $80 \%$ & 5 & 1 & $\mathrm{D}$ & 0,72 \\
\hline Hosjön & $\mathrm{C}$ & \begin{tabular}{|l|}
664693 \\
\end{tabular} & 163935 & $\mathrm{X}$ & & & 0,50 & 7 & - & 3 & 1 & $\mathrm{C}$ & 2,41 \\
\hline Borgsjön & $\mathrm{S}$ & 664974 & 131426 & & $\mathrm{X}$ & & - & 1 & $50 \%$ & 6 & 1 & $\mathrm{D}$ & 0,98 \\
\hline Sången & W & 671769 & 144429 & & $\mathrm{X}$ & $\mathrm{X}$ & - & 2 & $40 \%$ & 5 & 1 & C & 1,39 \\
\hline Övre Valsan & W & 672215 & 147386 & $\mathrm{X}$ & & & 0,78 & 9 & $33 \%$ & 6 & 1 & C & 1,21 \\
\hline Siljan & W & \begin{tabular}{|l|}
673490 \\
\end{tabular} & 145597 & $\mathrm{X}$ & $\mathrm{X}$ & $\mathrm{X}$ & 0,17 & 6 & - & 1 & (2) & A & 316,50 \\
\hline Tisjön & W & 676158 & 129183 & $\mathrm{X}$ & $\mathrm{X}$ & $\mathrm{X}$ & 0,11 & 9 & - & 4 & (3) & B & 22,93 \\
\hline Annsjön & $\mathrm{X}$ & 688945 & 156402 & $\mathrm{X}$ & & & 0,00 & 10 & - & 1 & 1 & $\mathrm{C}$ & 1,20 \\
\hline Öjen & $\mathrm{Y}$ & 690199 & 158016 & $\mathrm{X}$ & $\mathrm{X}$ & & 0,30 & 15 & - & 3 & 2 & $\mathrm{C}$ & 7,54 \\
\hline Klockesjön & $\mathrm{Y}$ & \begin{tabular}{|l|}
697440 \\
\end{tabular} & 160924 & $\mathrm{X}$ & & & 0,11 & 9 & - & 1 & 1 & D & - \\
\hline Stor-Habborn & $\mathrm{Y}$ & 697633 & 158415 & & $\mathrm{X}$ & & 0,00 & 7 & - & 0 & 1 & $\mathrm{D}$ & 0,28 \\
\hline Vågsfjärden & $\mathrm{Y}$ & 698062 & 162600 & $\mathrm{X}$ & $\mathrm{X}$ & & 0,43 & 7 & - & 2 & 1 & $\mathrm{C}$ & 3,63 \\
\hline Kindborgstjärnen & $\mathrm{Y}$ & 698112 & 163389 & & $\mathrm{X}$ & & 0,00 & 11 & - & 0 & 1 & $\mathrm{E}$ & 0,08 \\
\hline Nästvattnet & $\mathrm{Y}$ & 698133 & 159294 & $\mathrm{X}$ & & & 0,55 & 11 & $33 \%$ & 6 & 1 & $\mathrm{C}$ & 1,26 \\
\hline Lövsjön, Gallsäter & $\mathrm{Y}$ & 698203 & 161598 & $\mathrm{X}$ & & & 0,64 & 11 & $40 \%$ & 5 & 1 & $\mathrm{D}$ & - \\
\hline Mellan-Kroksjön & $\mathrm{Y}$ & 698404 & 157587 & $\mathrm{X}$ & & & 0,33 & 6 & - & 2 & 1 & $\mathrm{D}$ & - \\
\hline Valasjön & $\mathrm{Y}$ & 698918 & 158665 & & $\mathrm{X}$ & & 0,65 & 13 & $60 \%$ & 5 & 1 & $\mathrm{C}$ & 1,59 \\
\hline Lövsjön, Forsed & $\mathrm{Y}$ & 699031 & 158799 & $\mathrm{X}$ & & & 0,73 & 11 & $60 \%$ & 5 & 1 & $\mathrm{C}$ & 1,04 \\
\hline Lill-Åkersjön & $\mathrm{Y}$ & 699356 & 161493 & & $\mathrm{X}$ & $\mathrm{X}$ & 0,38 & 8 & - & 2 & 1 & $\mathrm{D}$ & 0,42 \\
\hline Idsjön & $\mathrm{Y}$ & 699867 & 160746 & $\mathrm{X}$ & & & 0,80 & 10 & $33 \%$ & 6 & 1 & $\mathrm{D}$ & - \\
\hline Gålsjön & $\mathrm{Y}$ & 700135 & 161219 & & $\mathrm{X}$ & & 0,06 & 9 & - & 1 & 2 & $\mathrm{C}$ & 3,34 \\
\hline Nydalasjön & $\mathrm{AC}$ & 708712 & 172291 & $\mathrm{X}$ & & & 0,34 & 7 & - & 1 & (3) & $\mathrm{C}$ & 1,59 \\
\hline
\end{tabular}

a Antalet par har bedömts med ledning av rapporteringen till Projekt LOM. Uppgifter inom parentes avser minimiskattningar, och rimligtvis finns fler stationära par i dessa sjöar. The number of pairs has been assessed with reference to the reporting from Projekt LOM. Figures in parentheses refer to minimum estimates, and it is quite likely that there are more resident pairs in these lakes.

b $\mathrm{A}=>100 \mathrm{~km}^{2}, \mathrm{~B}=10-100 \mathrm{~km}^{2}, \mathrm{C}=1-10 \mathrm{~km}^{2}, \mathrm{D}=0,1-1 \mathrm{~km}^{2}, \mathrm{E}=0,1-0,01 \mathrm{~km}^{2}$, enligt Svenskt Sjöregister (SMHI 1996). Ref. The Swedish National Lake Directory (SMHI 1996).

c Länskoder County codes: $\mathrm{AB}=$ Stockholm, $\mathrm{AC}=$ Västerbotten, $\mathrm{C}=$ Uppsala, $\mathrm{D}=$ Södermanland, $\mathrm{E}=$ Östergötland, $\mathrm{F}=$ Jönköping, $\mathrm{G}=$ Kronoberg, $\mathrm{H}=$ Kalmar, $\mathrm{K}=$ Blekinge, $\mathrm{M}=$ Skåne, $\mathrm{N}=$ Halland, $\mathrm{O}=$ Västra Götaland, $\mathrm{S}=$ Värmland, $\mathrm{T}=$ Örebro, $\mathrm{W}=$ Dalarna, $\mathrm{X}=\mathrm{Gävleborg,} \mathrm{Y}=$ Västernorrland. 
Appendix B.

Vattenkemi och absorbans (medelvärden från provtagningar 1995-2007, antal provtagningar inom parentes).

Water chemistry and absorbance (mean values of samplings from 1995-2007, number of samples in parentheses).

\begin{tabular}{|c|c|c|c|c|}
\hline $\begin{array}{l}\text { Sjö } \\
\text { Lake }\end{array}$ & $\mathrm{pH}$ & $\begin{array}{c}\text { Alkalinitet, mekv/1 } \\
\text { Alkalinity, meq/l }\end{array}$ & $\begin{array}{c}\text { Totalfosfor, } \mathrm{mg} / \mathrm{l} \\
\text { Total phosphorus, } \mathrm{mg} / \mathrm{l}\end{array}$ & $\begin{array}{l}\text { Absorbans, } \mathrm{f}_{250 / 5} \\
\text { Absorbance, } \mathrm{f}_{250 / 5}\end{array}$ \\
\hline Raslången & $6,54(2)$ & $0,144(2)$ & $0,008(2)$ & $0,099(2)$ \\
\hline Immeln & $6,73(3)$ & $0,122(3)$ & $0,010(3)$ & $0,110(3)$ \\
\hline Rössjön & $6,96(3)$ & $0,178(3)$ & $0,017(3)$ & $0,089(3)$ \\
\hline Värsjö & $6,84(2)$ & $0,140(2)$ & $0,011(2)$ & $0,062(2)$ \\
\hline Fedingesjön & $6,38(3)$ & $0,094(3)$ & $0,023(3)$ & $0,384(3)$ \\
\hline Valasjön / Dagsås & $6,17(3)$ & $0,077(3)$ & $0,006(3)$ & 0,049 (3) \\
\hline Hurven & $6,82(3)$ & $0,157(3)$ & 0,007 (3) & $0,127(3)$ \\
\hline Stora Neten & $6,79(2)$ & $0,128(2)$ & $0,005(2)$ & $0,037(2)$ \\
\hline Norra Svansjön & $6,48(2)$ & $0,114(2)$ & $0,010(2)$ & $0,109(2)$ \\
\hline Fegen & $6,46(2)$ & $0,112(2)$ & $0,008(2)$ & $0,155(2)$ \\
\hline Grysjön & $6,97(3)$ & $0,287(3)$ & - & $0,387(3)$ \\
\hline Yttre Älvsjön & $6,10(2)$ & $0,070(2)$ & - & $0,210(2)$ \\
\hline Älgsjön / Öxabäck & $7,17(3)$ & $0,590(3)$ & - & $0,057(3)$ \\
\hline Stora Horredsjön & $6,91(2)$ & $0,251(2)$ & $0,007(2)$ & $0,059(2)$ \\
\hline Öxasjön & $7,20(3)$ & $0,413(3)$ & - & $0,180(3)$ \\
\hline Lövsjö & $6,12(3)$ & $0,036(3)$ & $0,006(3)$ & $0,061(3)$ \\
\hline Mycklaflon & $7,23(3)$ & $0,318(3)$ & $0,007(3)$ & $0,053(3)$ \\
\hline Gissen & $6,86(3)$ & $0,271(3)$ & $0,008(3)$ & $0,052(3)$ \\
\hline Södra Vixen & $7,21(4)$ & $0,380(4)$ & $0,013(4)$ & $0,035(4)$ \\
\hline Frisjön & $6,43(3)$ & $0,130(3)$ & - & $0,167(3)$ \\
\hline Västra (Yttre) Ingsjön & $6,75(2)$ & $0,157(2)$ & $0,008(2)$ & $0,127(2)$ \\
\hline Norra Vixen & $7,22(2)$ & $0,722(2)$ & $0,015(2)$ & $0,043(2)$ \\
\hline Nässjasjön & $7,00(3)$ & $0,308(3)$ & $0,016(3)$ & $0,278(3)$ \\
\hline Storsjön / Viskafors & $6,51(2)$ & $0,121(2)$ & $0,008(2)$ & $0,148(2)$ \\
\hline Hunsnäsen & $7,05(2)$ & $0,522(2)$ & $0,021(2)$ & $0,201(2)$ \\
\hline Finnsjön & $6,53(3)$ & $0,144(3)$ & - & $0,137(3)$ \\
\hline Yxsjön & $6,81(2)$ & $0,257(2)$ & $0,007(2)$ & $0,106(2)$ \\
\hline Trehörningen / Komosse & $6,95(2)$ & $0,317(2)$ & $0,013(2)$ & $0,161(2)$ \\
\hline Viaredssjön & $6,76(3)$ & $0,206(3)$ & 0,009 (3) & $0,123(3)$ \\
\hline Pickesjön & $6,80(2)$ & $0,175(2)$ & - & $0,060(2)$ \\
\hline Östra Nedsjön & $6,85(2)$ & $0,195(2)$ & - & $0,060(2)$ \\
\hline Hornasjön & $6,95(2)$ & $0,270(2)$ & - & $0,110(2)$ \\
\hline Sandsjön / Härryda & $6,77(3)$ & $0,177(3)$ & - & $0,087(3)$ \\
\hline Stora Sturven & $6,97(3)$ & $0,234(3)$ & $0,006(3)$ & $0,089(3)$ \\
\hline Tvärsjön & $6,86(2)$ & $0,179(2)$ & $0,005(2)$ & $0,062(3)$ \\
\hline Vibosjön & $6,77(3)$ & $0,247(3)$ & - & $0,113(3)$ \\
\hline Uspen & $7,30(3)$ & $0,350(3)$ & - & $0,063(3)$ \\
\hline Västra Lägern & $7,22(3)$ & $0,343(3)$ & $0,007(3)$ & $0,065(3)$ \\
\hline Sälsjön & $6,87(2)$ & $0,354(2)$ & $0,007(2)$ & $0,096(2)$ \\
\hline Brängen & $7,14(3)$ & $0,313(3)$ & $0,012(3)$ & $0,128(3)$ \\
\hline Stora Öjasjön / Hökensås & $6,78(4)$ & $0,205(4)$ & $0,008(4)$ & $0,068(4)$ \\
\hline Stora Holmevatten / Kynnefjäll & $6,05(2)$ & $0,115(2)$ & - & $0,090(2)$ \\
\hline Skottbackatjärn & $7,00(3)$ & $0,207(3)$ & - & $0,070(3)$ \\
\hline Fjättersjön & $7,01(3)$ & $0,331(3)$ & $0,021(3)$ & $0,059(3)$ \\
\hline Sottern & $7,41(3)$ & $0,564(3)$ & $0,020(3)$ & 0,079 (3) \\
\hline Valsebotjärn & $6,80(3)$ & $0,183(3)$ & - & $0,117(3)$ \\
\hline Teen & $6,43(4)$ & $0,100(4)$ & $0,023(4)$ & $0,237(4)$ \\
\hline Acksjön & $6,84(3)$ & $0,245(3)$ & 0,009 (3) & $0,131(3)$ \\
\hline
\end{tabular}




\begin{tabular}{lcccc}
\hline $\begin{array}{l}\text { Sjö } \\
\text { Lake }\end{array}$ & $\mathrm{pH}$ & $\begin{array}{c}\text { Alkalinitet, mekv/l } \\
\text { Alkalinity, meq/l }\end{array}$ & $\begin{array}{c}\text { Totalfosfor, } \mathrm{mg} / \mathrm{l} \\
\text { Total phosphorus, } m g / l\end{array}$ & $\begin{array}{c}\text { Absorbans, } \mathrm{f}_{250 / 5} \\
\text { Absorbance, } f_{250 / 5}\end{array}$ \\
\hline Lilla Ulvattnet & $6,67(3)$ & $0,177(3)$ & - & $0,157(3)$ \\
Gravdalssjön & $7,00(3)$ & $0,190(3)$ & $0,007(2)$ & $0,029(3)$ \\
\hline Näshultasjön & $6,93(3)$ & $0,460(3)$ & $0,025(3)$ & $0,106(3)$ \\
Bornsjön & $7,77(3)$ & $1,275(3)$ & $0,032(3)$ & $0,025(3)$ \\
Kullaträsket & $6,86(2)$ & $0,340(2)$ & $0,010(2)$ & $0,094(2)$ \\
Aspviksträsket & $7,54(3)$ & $1,297(3)$ & $0,029(3)$ & $0,061(3)$ \\
Stora Le & $6,74(3)$ & $0,091(3)$ & $0,005(3)$ & $0,049(3)$ \\
\hline Träskjöön & $7,71(3)$ & $0,982(3)$ & $0,019(3)$ & $0,067(3)$ \\
Tärnan & $7,03(3)$ & $0,334(3)$ & $0,010(3)$ & $0,074(3)$ \\
Malmsjön & $7,37(2)$ & $0,410(2)$ & $0,024(2)$ & $0,053(2)$ \\
Saxen & $6,76(3)$ & $0,199(3)$ & $0,005(3)$ & $0,073(3)$ \\
Ösmaren & $7,96(3)$ & $2,290(3)$ & $0,030(3)$ & $0,082(3)$ \\
\hline Hosjön & $7,64(3)$ & $1,361(3)$ & $0,018(3)$ & $0,057(3)$ \\
Övre Valsan & $6,92(3)$ & $0,165(3)$ & $0,010(3)$ & $0,069(3)$ \\
Siljan & $6,99(2)$ & $0,154(2)$ & $0,008(2)$ & $0,083(2)$ \\
Tisjön & $6,67(2)$ & $0,081(2)$ & $0,010(2)$ & $0,085(2)$ \\
Annsjön & $6,94(3)$ & $0,194(3)$ & $0,020(3)$ & $0,178(3)$ \\
\hline Öjen & $7,00(2)$ & $0,250(2)$ & $0,010(2)$ & $0,101(2)$ \\
Klockesjön & $6,69(2)$ & $0,136(2)$ & $0,012(2)$ & $0,083(2)$ \\
Vågsfjärden & $7,00(3)$ & $0,274(3)$ & $0,014(3)$ & $0,041(3)$ \\
Nästvattnet & $6,95(2)$ & $0,156(2)$ & $0,007(2)$ & $0,112(2)$ \\
Lövsjön / Gallsäter & $6,91(3)$ & $0,200(3)$ & $0,010(3)$ & $0,118(3)$ \\
\hline Mellan-Kroksjön & $6,65(4)$ & $0,083(4)$ & $0,010(4)$ & $0,217(4)$ \\
Lövsjön / Forsed & $6,82(2)$ & $0,152(2)$ & $0,008(2)$ & $0,131(2)$ \\
Idsjön & $6,62(2)$ & $0,086(2)$ & $0,014(2)$ & $0,160(2)$ \\
Nydalasjön & $6,46(2)$ & $0,157(2)$ & $0,010(2)$ & $0,063(2)$ \\
\hline
\end{tabular}




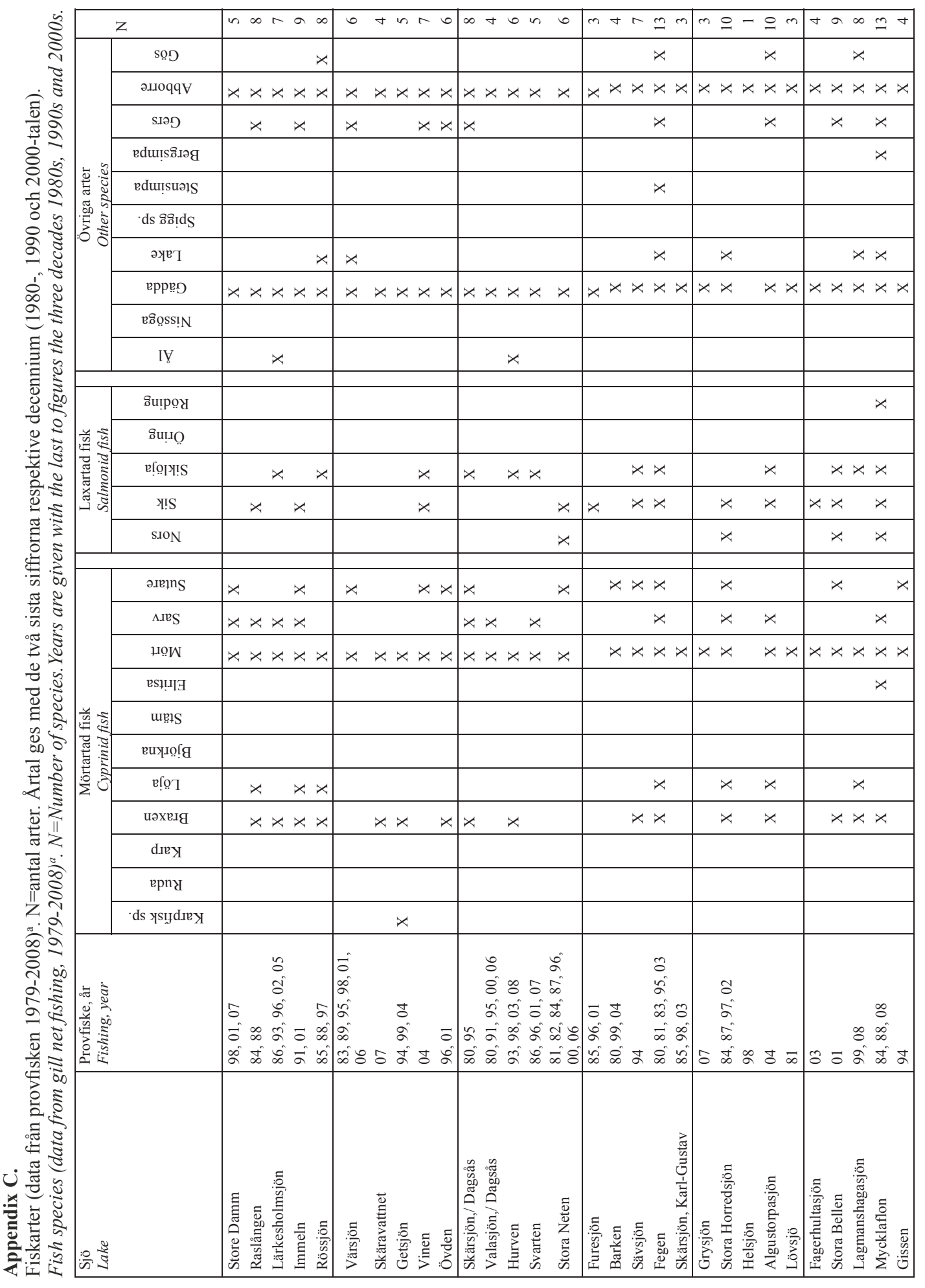




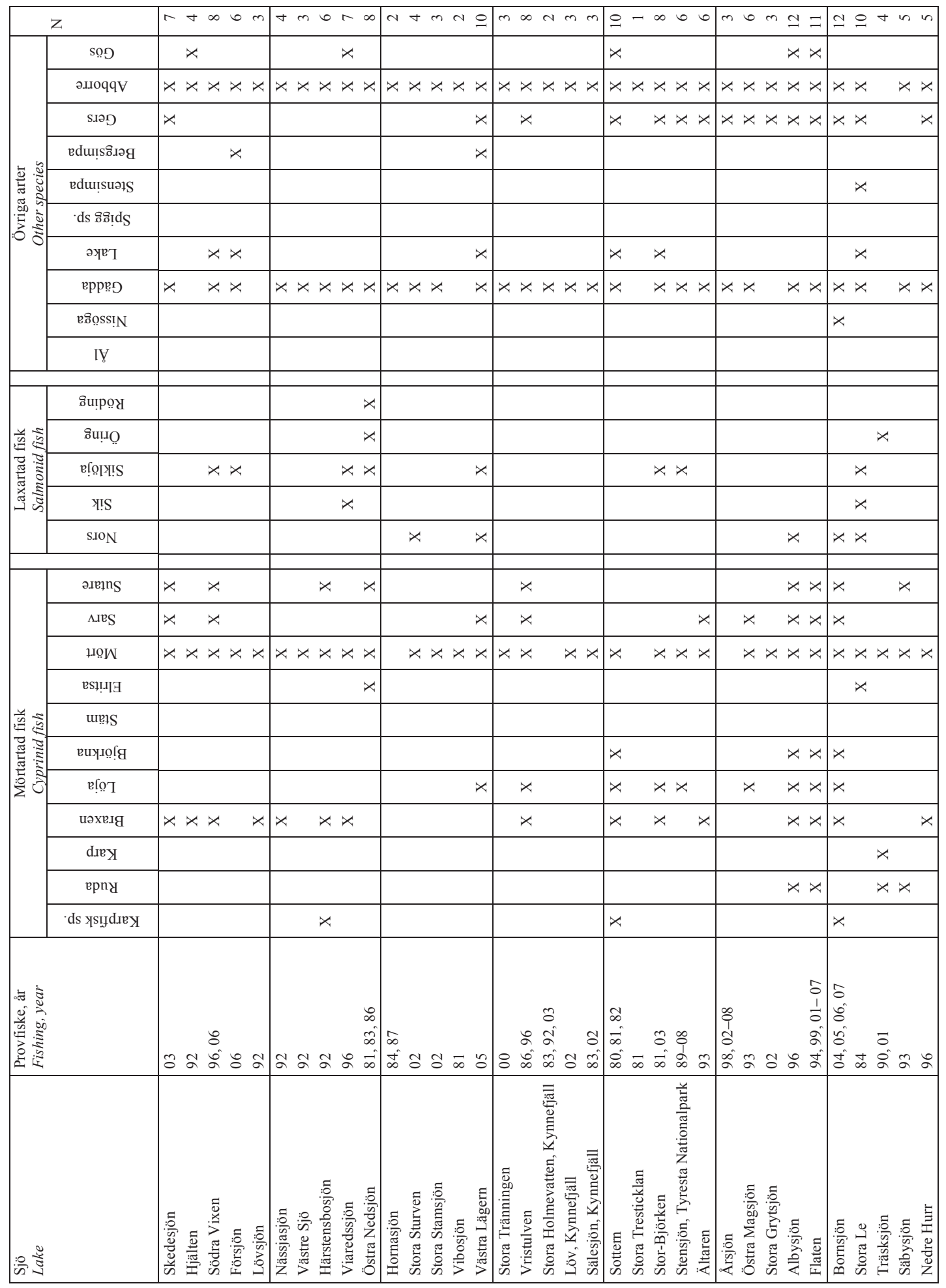




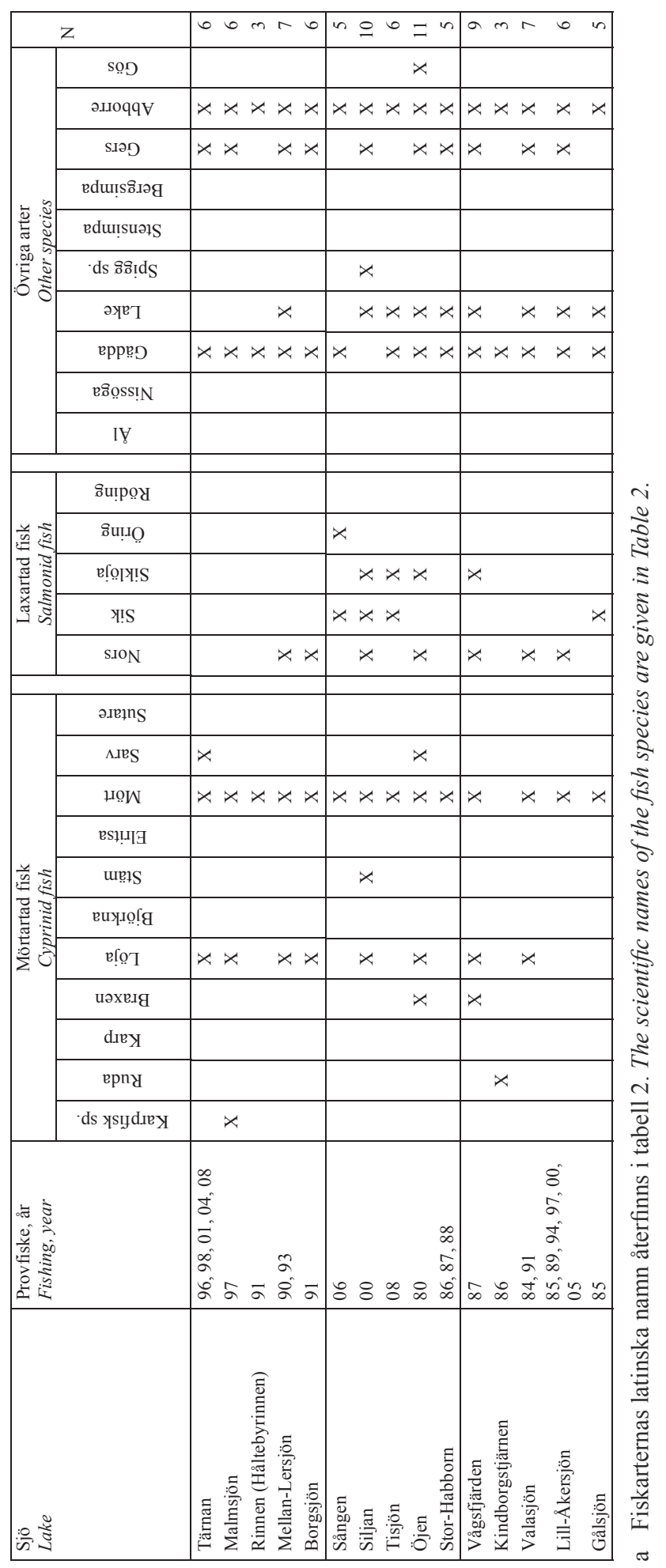

29 
Appendix D.

Siktdjup och provfiskeresultat med bottensatta nät (data från 1994-2008).

Secchi disc transparency and results from gill net fishing with bottom-placed nets (data from 1994-2008).

\begin{tabular}{|c|c|c|c|c|c|c|c|c|c|c|c|c|c|c|c|c|c|}
\hline \multirow{3}{*}{\begin{tabular}{|l} 
Sjö \\
\\
Lake
\end{tabular}} & \multirow{3}{*}{$\begin{array}{c}\text { Sikt- } \\
\text { djup } \\
\text { Secchi } \\
\text { disc } \\
\text { transp- } \\
\text { arency } \\
m^{a}{ }^{a}\end{array}$} & \multirow{3}{*}{$\begin{array}{c}\text { Antal } \\
\text { prov- } \\
\text { fis- } \\
\text { ken } \\
\text { No. } \\
\text { of } \\
\text { fish- } \\
\text { ings }\end{array}$} & \multirow{3}{*}{$\begin{array}{c}\text { Antal } \\
\text { nät } \\
\\
\text { No. } \\
\text { of } \\
\text { nets }\end{array}$} & \multicolumn{7}{|c|}{$\begin{array}{l}\text { Medelantal per nätansträngning, all fisk } \\
\text { Mean number per catch effort, all fish }\end{array}$} & \multicolumn{7}{|c|}{$\begin{array}{l}\text { Medelantal per nätansträngning, fisk }<22 \mathrm{~cm} \\
\text { Mean number per catch effort, fish }<22 \mathrm{~cm}\end{array}$} \\
\hline & & & & Total & $\begin{array}{c}\text { Abb- } \\
\text { orre }\end{array}$ & $\begin{array}{l}\text { Mört- } \\
\text { artad }\end{array}$ & $\begin{array}{l}\text { Lax- } \\
\text { artad }\end{array}$ & Gers & Gädda & $\begin{array}{c}\text { Övrig } \\
\text { fisk }\end{array}$ & Total & $\begin{array}{c}\text { Abb- } \\
\text { orre }\end{array}$ & $\begin{array}{l}\text { Mört- } \\
\text { artad }\end{array}$ & $\begin{array}{l}\text { Lax- } \\
\text { artad }\end{array}$ & Gers & Gädda & $\begin{array}{c}\text { Övrig } \\
\text { fisk }\end{array}$ \\
\hline & & & & Total & Perch & $\begin{array}{l}\text { Cypr- } \\
\text { inid }\end{array}$ & $\begin{array}{l}\text { Salm- } \\
\text { onid }\end{array}$ & Ruffe & Pike & $\begin{array}{l}\text { Other } \\
\text { fish }\end{array}$ & Total & Perch & $\begin{array}{l}\text { Cypr- } \\
\text { inid }\end{array}$ & $\begin{array}{l}\text { Salm- } \\
\text { onid }\end{array}$ & Ruffe & Pike & $\begin{array}{l}\text { Other } \\
\text { fish }\end{array}$ \\
\hline Store Damm & $1,2(3)$ & 3 & 16 & 40,15 & 14,96 & 25,04 & 0,00 & 0,00 & 0,15 & 0,00 & 35,41 & 10,64 & 24,77 & 0,00 & 0,00 & 0,00 & 0,00 \\
\hline Lärkesholmssjön & $1,7(4)$ & 4 & 24 & 26,56 & 12,12 & 14,22 & 0,06 & 0,00 & 0,16 & 0,00 & 22,34 & 11,46 & 10,82 & 0,06 & 0,00 & 0,00 & 0,00 \\
\hline Immeln & $3,9(1)$ & 1 & 56 & 20,20 & 12,29 & 3,99 & 1,54 & 2,36 & 0,02 & 0,00 & 19,16 & 11,56 & 3,70 & 1,54 & 2,36 & 0,00 & 0,00 \\
\hline Rössjön & $3,0(1)$ & 1 & 48 & 27,06 & 12,75 & 13,04 & 1,13 & 0,00 & 0,08 & 0,06 & 20,86 & 11,57 & 8,10 & 1,13 & 0,00 & 0,02 & 0,04 \\
\hline Värsjö & $3,1(4)$ & 4 & 24 & 70,00 & 35,19 & 26,85 & 0,00 & 7,68 & 0,28 & 0,00 & 66,50 & 33,30 & 25,43 & 0,00 & 7,68 & 0,09 & 0,00 \\
\hline Skäravattnet & $1,5(1)$ & 1 & 16 & 13,76 & 6,69 & 6,69 & 0,00 & 0,00 & 0,38 & 0,00 & 10,31 & 4,94 & 5,37 & 0,00 & 0,00 & 0,00 & 0,00 \\
\hline Getsjön & $2,8(2)$ & 3 & $16-24$ & 27,51 & 12,37 & 14,85 & 0,00 & 0,00 & 0,29 & 0,00 & 25,27 & 11,15 & 14,12 & 0,00 & 0,00 & 0,00 & 0,00 \\
\hline Vinen & 3,1 (1) & 1 & 24 & 29,17 & 13,83 & 10,50 & 0,54 & 4,13 & 0,17 & 0,00 & 26,50 & 11,41 & 10,46 & 0,50 & 4,13 & 0,00 & 0,00 \\
\hline Övden & $2,8(2)$ & 2 & $16-24$ & 27,61 & 16,47 & 8,95 & 0,00 & 2,04 & 0,15 & 0,00 & 24,71 & 15,65 & 7,02 & 0,00 & 2,04 & 0,00 & 0,00 \\
\hline Skärsjön, Dagsås & $8,5(1)$ & 1 & 48 & 30,97 & 20,98 & 7,53 & 1,13 & 1,29 & 0,04 & 0,00 & 24,18 & 16,23 & 5,58 & 1,08 & 1,29 & 0,00 & 0,00 \\
\hline Valasjön, Dagsås & $5,9(3)$ & 3 & $8-34$ & 20,89 & 13,35 & 7,34 & 0,00 & 0,00 & 0,20 & 0,00 & 20,26 & 13,12 & 7,10 & 0,00 & 0,00 & 0,04 & 0,00 \\
\hline Hurven & $2,7(3)$ & 3 & 38 & 19,69 & 11,09 & 5,30 & 3,23 & 0,00 & 0,06 & 0,01 & 17,58 & 10,65 & 3,69 & 3,23 & 0,00 & 0,01 & 0,00 \\
\hline Svarten & $5,4(3)$ & 3 & $8-40$ & 19,32 & 16,46 & 2,59 & 0,08 & 0,00 & 0,19 & 0,00 & 17,09 & 14,80 & 2,25 & 0,00 & 0,00 & 0,04 & 0,00 \\
\hline Stora Neten & $8,7(3)$ & 3 & $16-56$ & 15,08 & 9,62 & 4,40 & 0,99 & 0,00 & 0,07 & 0,00 & 13,18 & 9,14 & 3,52 & 0,51 & 0,00 & 0,01 & 0,00 \\
\hline Furesjön, Nösslinge & $9,8(2)$ & 2 & 4 & 20,13 & 19,75 & 0,00 & 0,38 & 0,00 & 0,00 & 0,00 & 15,88 & 15,88 & 0,00 & 0,00 & 0,00 & 0,00 & 0,00 \\
\hline Barken & $2,9(2)$ & 2 & 8 & 18,15 & 13,82 & 4,26 & 0,00 & 0,00 & 0,07 & 0,00 & 16,51 & 12,38 & 4,13 & 0,00 & 0,00 & 0,00 & 0,00 \\
\hline Sävsjön & $3,5(1)$ & 1 & 32 & 25,41 & 6,84 & 11,03 & 7,38 & 0,00 & 0,16 & 0,00 & 24,23 & 6,33 & 10,79 & 7,11 & 0,00 & 0,00 & 0,00 \\
\hline Fegen & 3,1 (3) & 3 & $32-80$ & 34,92 & 16,74 & 7,75 & 4,17 & 5,93 & 0,03 & 0,30 & 33,53 & 16,12 & 7,27 & 4,06 & 5,93 & 0,00 & 0,15 \\
\hline $\begin{array}{l}\text { Skärsjön, Karl- } \\
\text { Gustav }\end{array}$ & $3,4(2)$ & 2 & $4-8$ & 30,14 & 24,69 & 5,07 & 0,00 & 0,00 & 0,38 & 0,00 & 28,32 & 23,44 & 4,81 & 0,00 & 0,00 & 0,07 & 0,00 \\
\hline Grysjön & $0,8(1)$ & 1 & 24 & 13,04 & 5,00 & 7,96 & 0,00 & 0,00 & 0,08 & 0,00 & 12,17 & 4,42 & 7,75 & 0,00 & 0,00 & 0,00 & 0,00 \\
\hline Stora Horredsjön & $6,6(2)$ & 2 & 48 & 28,04 & 20,85 & 5,92 & 1,07 & 0,00 & 0,15 & 0,05 & 24,49 & 19,40 & 4,27 & 0,77 & 0,00 & 0,02 & 0,03 \\
\hline Helsjön & $10,5(1)$ & 1 & 4 & 19,50 & 19,50 & 0,00 & 0,00 & 0,00 & 0,00 & 0,00 & 19,25 & 19,25 & 0,00 & 0,00 & 0,00 & 0,00 & 0,00 \\
\hline Algutstorpasjön & $1,4(1)$ & 1 & 24 & 17,33 & 5,38 & 7,33 & 0,92 & 3,58 & 0,08 & 0,04 & 15,09 & 3,49 & 7,10 & 0,92 & 3,58 & 0,00 & 0,00 \\
\hline Fagerhultasjön & 3,1 (1) & 1 & 24 & 36,33 & 28,29 & 7,08 & 0,88 & 0,00 & 0,08 & 0,00 & 33,58 & 25,87 & 6,83 & 0,88 & 0,00 & 0,00 & 0,00 \\
\hline Stora Bellen & $2,5(1)$ & 1 & 48 & 27,84 & 8,67 & 4,26 & 1,52 & 13,31 & 0,08 & 0,00 & 27,35 & 8,41 & 4,13 & 1,50 & 13,31 & 0,00 & 0,00 \\
\hline Lagmanshagasjön & $1,8(2)$ & 2 & $38-40$ & $\begin{array}{l}19,89 \\
\end{array}$ & 10,55 & 3,99 & 4,28 & 0,00 & 0,04 & 1,03 & 17,65 & $\begin{array}{ll}9,68 \\
\end{array}$ & 3,43 & 4,28 & 0,00 & 0,02 & 0,24 \\
\hline Mycklaflon & $5,8(1)$ & 1 & 56 & 28,10 & 9,13 & 3,54 & 3,96 & 11,36 & 0,02 & 0,09 & 25,97 & 8,04 & 2,81 & 3,72 & 11,36 & 0,00 & 0,04 \\
\hline Gissen & $3,6(1)$ & 1 & 32 & 18,75 & 12,94 & 5,59 & 0,00 & 0,00 & 0,22 & 0,00 & 16,60 & 12,63 & 3,97 & 0,00 & 0,00 & 0,00 & 0,00 \\
\hline Skedesjön & $1,8(1)$ & 1 & 32 & 38,78 & 16,84 & 16,47 & 0,00 & 5,31 & 0,16 & 0,00 & 35,95 & 15,84 & 14,80 & 0,00 & 5,31 & 0,00 & 0,00 \\
\hline Södra Vixen & $4,0(2)$ & 2 & 40 & 34,91 & 17,08 & 17,61 & 0,04 & 0,00 & 0,16 & 0,02 & 32,51 & 15,19 & 17,24 & 0,04 & 0,00 & 0,02 & 0,02 \\
\hline Försjön & $4,5(1)$ & 1 & 40 & 9,69 & 5,83 & 2,40 & 1,33 & 0,00 & 0,05 & 0,08 & 8,92 & 5,33 & 2,23 & 1,30 & 0,00 & 0,00 & 0,06 \\
\hline Stora Sturven & $4,0(1)$ & 1 & 40 & 14,12 & 6,53 & 6,23 & 1,33 & 0,00 & 0,03 & 0,00 & 12,58 & 5,70 & 5,55 & 1,33 & 0,00 & 0,00 & 0,00 \\
\hline Stora Stamsjön & $2,6(1)$ & 1 & 24 & 31,38 & 26,33 & 4,92 & 0,00 & 0,00 & 0,13 & 0,00 & 27,63 & 23,38 & 4,25 & 0,00 & 0,00 & 0,00 & 0,00 \\
\hline Västra Lägern & $3,2(1)$ & 1 & 56 & 24,17 & 12,80 & 5,18 & 0,86 & 5,16 & 0,05 & 0,12 & 23,50 & 12,32 & 5,09 & 0,86 & 5,16 & 0,00 & 0,07 \\
\hline Stora Tränningen & $1,4(1)$ & 1 & 24 & 36,55 & 24,25 & 11,92 & 0,00 & 0,00 & 0,38 & 0,00 & 33,75 & 22,96 & 10,79 & 0,00 & 0,00 & 0,00 & 0,00 \\
\hline Vristulven & $2,5(1)$ & 1 & 32 & 48,00 & 29,34 & 12,19 & 0,00 & 6,34 & 0,13 & 0,00 & 47,19 & 28,75 & 12,10 & 0,00 & 6,34 & 0,00 & 0,00 \\
\hline $\begin{array}{l}\text { St. Holmevatten, } \\
\text { Kynnefjäll }\end{array}$ & $4,7(1)$ & 1 & 22 & 20,69 & 20,55 & 0,00 & 0,00 & 0,00 & 0,14 & 0,00 & 18,05 & 18,05 & 0,00 & 0,00 & 0,00 & 0,00 & 0,00 \\
\hline Löv, Kynnefjäll & $3,5(1)$ & 1 & 16 & 38,44 & 18,44 & 19,94 & 0,00 & 0,00 & 0,06 & 0,00 & 36,37 & 16,81 & 19,56 & 0,00 & 0,00 & 0,00 & 0,00 \\
\hline Sälesjön, Kynnefjäll & $1,6(1)$ & 1 & 16 & 26,20 & 15,94 & 9,88 & 0,00 & 0,00 & 0,38 & 0,00 & 22,43 & 12,87 & 9,56 & 0,00 & 0,00 & 0,00 & 0,00 \\
\hline Stor-Björken & $2,2(1)$ & 1 & 7 & 50,14 & 6,43 & 19,00 & 19,57 & 5,00 & 0,14 & 0,00 & 50,14 & 6,43 & 19,00 & 19,57 & 5,00 & 0,14 & 0,00 \\
\hline Stensjön, Tyresta & $3,9(15)$ & 15 & 24 & 36,32 & 7,81 & 24,17 & 1,17 & 3,08 & 0,09 & 0,00 & 32,60 & 6,84 & 21,50 & 1,17 & 3,08 & 0,01 & 0,00 \\
\hline Årsjön & $3,9(8)$ & 8 & 8 & 21,15 & 19,94 & 0,00 & 0,00 & 1,16 & 0,05 & 0,00 & 19,79 & 18,61 & 0,00 & 0,00 & 1,16 & 0,02 & 0,00 \\
\hline Stora Grytsjön & $1,1(1)$ & 1 & 8 & 34,38 & 12,50 & 18,75 & 0,00 & 3,13 & 0,00 & 0,00 & 32,76 & 11,38 & 18,25 & 0,00 & 3,13 & 0,00 & 0,00 \\
\hline Albysjön & $0,8(1)$ & 1 & 24 & 73,80 & 11,13 & 61,25 & 0,21 & 1,04 & 0,04 & 0,13 & 49,56 & 9,76 & 38,55 & 0,21 & 1,04 & 0,00 & 0,00 \\
\hline Flaten & $6,0(9)$ & 7 & 24 & 57,79 & 21,44 & 35,65 & 0,00 & 0,63 & 0,05 & 0,02 & 52,67 & 18,79 & 33,24 & 0,00 & 0,63 & 0,00 & 0,01 \\
\hline Bornsjön & $5,7(4)$ & 4 & 40 & 52,06 & 27,83 & 15,28 & 2,12 & 6,67 & 0,11 & 0,05 & 48,05 & 27,28 & 11,92 & 2,12 & 6,67 & 0,01 & 0,05 \\
\hline Träsksjön & $1,7(1)$ & 1 & 8 & 75,76 & 0,00 & 75,76 & 0,00 & 0,00 & 0,00 & 0,00 & 75,38 & 0,00 & 75,38 & 0,00 & 0,00 & 0,00 & 0,00 \\
\hline Nedre Hurr & $2,7(1)$ & 1 & 24 & 21,42 & 14,88 & 4,75 & 0,00 & 1,50 & 0,29 & 0,00 & 19,24 & 13,87 & 3,87 & 0,00 & 1,50 & 0,00 & 0,00 \\
\hline Tärnan & $3,3(4)$ & 4 & 24 & 45,79 & 17,57 & 25,49 & 0,00 & 2,54 & 0,19 & 0,00 & 44,69 & 17,07 & 25,06 & 0,00 & 2,54 & 0,02 & 0,00 \\
\hline Malmsjön & $4,3(1)$ & 1 & 16 & 82,08 & 38,38 & 40,51 & 0,00 & 3,13 & 0,06 & 0,00 & 78,08 & 35,25 & 39,70 & 0,00 & 3,13 & 0,00 & 0,00 \\
\hline Sången & $4,0(1)$ & 1 & 40 & 12,48 & 10,95 & 1,43 & 0,05 & 0,00 & 0,05 & 0,00 & 11,55 & 10,30 & 1,25 & 0,00 & 0,00 & 0,00 & 0,00 \\
\hline Siljan & $5,0(1)$ & 1 & 24 & 20,20 & 8,88 & 1,25 & 1,99 & 8,00 & 0,00 & 0,08 & 19,11 & 8,08 & 1,20 & 1,79 & 8,00 & 0,00 & 0,04 \\
\hline Tisjön & $2,6(1)$ & 1 & 40 & 19,87 & 12,48 & 6,25 & 1,08 & 0,00 & 0,03 & 0,03 & 17,63 & 10,47 & 6,18 & 0,98 & 0,00 & 0,00 & 0,00 \\
\hline Lill-Åkersjön & $4,1(1)$ & 4 & $4-24$ & 15,12 & 8,34 & 5,60 & 0,35 & 0,64 & 0,07 & 0,12 & 12,31 & 5,71 & 5,58 & 0,35 & 0,64 & 0,00 & 0,03 \\
\hline
\end{tabular}

a Antal mätningar inom parentes. Siffrorna avser medelvärden för sjöar med mer än en mätning.

Number of measurements is given in parentheses. The figures represent the mean values for lakes with more than one measurement. 